Florida International University FIU Digital Commons

$11-10-2010$

\title{
Mediational Effects in Cognitive Behavioral Treatment for Anxiety Disorders in Children and Adolescents
}

Sandra Williams

Florida International University, swill003@fiu.edu

DOI: $10.25148 /$ etd.FI10120805

Follow this and additional works at: https://digitalcommons.fiu.edu/etd

\section{Recommended Citation}

Williams, Sandra, "Mediational Effects in Cognitive Behavioral Treatment for Anxiety Disorders in Children and Adolescents" (2010). FIU Electronic Theses and Dissertations. 323.

https://digitalcommons.fiu.edu/etd/323 


\title{
FLORIDA INTERNATIONAL UNIVERSITY
}

Miami, Florida

\section{MEDIATIONAL EFFECTS IN COGNITIVE BEHAVIORAL TREATMENT FOR ANXIETY DISORDERS IN CHILDREN AND ADOLESCENTS}

\author{
A dissertation submitted in partial fulfillment of the \\ requirements for the degree of \\ DOCTOR OF PHILOSOPHY \\ in \\ PSYCHOLOGY \\ by \\ Sandra Williams
}

2010 
To: Dean Kenneth G. Furton

College of Arts and Sciences

This dissertation, written by Sandra Williams and entitled Mediational Effects in Cognitive Behavioral Treatment for Anxiety Disorders in Children and Adolescents, having been approved in respect to style and intellectual content, is referred to you for judgment.

We have read this dissertation and recommend that it be approved.

William M. Kurtines

Maureen Kenny

Wendy K. Silverman, Co-Major Professor

James Jaccard, Co-Major Professor

Date of Defense: November 10, 2010

The dissertation of Sandra Williams is approved.

\begin{tabular}{r}
$\begin{array}{r}\text { Dean Kenneth G. Furton } \\
\text { College of Arts and Sciences }\end{array}$ \\
\hline Interim Dean Kevin O'Shea \\
University Graduate School
\end{tabular}

Florida International University, 2010 


\section{DEDICATION}

I dedicate this dissertation to my wonderful family. In particular, my husband Khale, whose love, guidance, and support carried me through this educational journey. I must also dedicate this dissertation to my loving parents who never complained about those long nights of baby-sitting. It was your countless sacrifices, encouragement, and endless support that allowed me to reach this accomplishment. To my awesome in-laws who have given me their fullest support. To my fabulous sisters who cheered me on along the way. To my amazing children, Kayla, Seth, Blake, and Aiden whose encouraging smiles and priceless hugs during tough times kept me focused. 


\section{ACKNOWLEDGMENTS}

I would like to thank the members of my committee, Dr. William Kurtines and Dr. Maureen C. Kenny, and my major professors Dr. Wendy K. Silverman and Dr. James Jaccard for all of their guidance and support.

My deepest gratitude is to my major professor and advisor Dr. Wendy K.

Silverman. I have been amazingly fortunate to have an advisor who guided me with care and patience. Your support and direction played an integral part in my excellent graduate experience. I will forever be grateful for your mentorship.

I am so grateful to Dr. James Jaccard. I owe my growth in the area of statistics and methodology to you. Your training has cultivated my desire to learn more. Thank you for your continued support and guidance.

Special thanks to my support team and good friends, Rona Carter, Calonie Gray, Sabrina Des Rosier, and Guitele Rahill. Thank you for your friendship and support throughout this process. Thank you to everyone at CAPP. I enjoyed working with you all.

I extend my appreciation to my sisters, Myrlande, Nancy, Marjorie, Regine, and Martine. You all have guided and supported me. Thank you to my parents for always encouraging me to learn and to reach my highest potential.

Finally, I would like to acknowledge the financial support I received from the Florida Education Fund. Special thanks to the McKnight family, especially Charles Jackson, for the great emotional support extended towards me. 
ABSTRACT OF THE DISSERTATION

MEDIATIONAL EFFECTS IN

COGNITIVE BEHAVIORAL TREATMENT FOR

ANXIETY DISORDERS IN CHILDREN AND ADOLESCENTS

by

Sandra Williams

Florida International University, 2010

Miami, Florida

Professor Wendy K. Silverman, Co-Major Professor

Professor James Jaccard, Co-Major Professor

The current study examined whether variables that have been found to influence treatment outcome serve as mediators of a child and adolescent cognitive behavioral treatment (CBT) anxiety program at multiple time points throughout the intervention. The study also examined mediating variables measured at multiple time points during treatment to determine the time lags necessary for changes in the mediator variable to translate into changes on treatment gains. Participants were 168 youth (ages 6 to 16 years; $54 \%$ males) and their mothers who presented to the Child Anxiety and Phobia Program (CAPP) at Florida International University (FIU).

Overall, results indicate that the mediators at multiple time points influenced youth anxiety in a fluctuating manner, such that a decrease in skills at one given session caused changes in youth anxiety at a later session. This dynamic between the mediator and outcome may be reflective of the process of therapeutic change and suggests that skills gained from session to session took time to exert their effect on youth anxiety. The 
methodology employed helps to elucidate how variables mediate treatment outcome in youth anxiety disorders. 


\section{TABLE OF CONTENTS}

CHAPTER

PAGE

I. INTRODUCTION

Cognitive Behavioral Treatment for Reducing Anxiety Disorders

Mediators and Mechanism of Therapeutic Change

Why Study Mediation?

Testing for Mediation: The Exception Rather Than the Rule

Mediators of Treatment Outcome in CBT for Youth Anxiety

Disorders

Cross-sectional vs Longitudinal Data to Test Mediation

II. LITERATURE REVIEW

Psychosocial Interventions for Childhood Anxiety Disorders 9

Parental Involvement in Child Anxiety Treatment 9

Parent and Peer Childhood Anxiety Group Treatment 20

Peer Involvement in Youth Anxiety Treatment 23

$\begin{array}{ll}\text { Summary of Treatment Studies } & 28\end{array}$

Mediators of Treatment Outcome in Youth Anxiety Literature 28

Parenting Variables as a Mediators of Treatment Outcome 28

$\begin{array}{ll}\text { Cognitive Variables as Mediators of Treatment Outcome } & 29\end{array}$

Peer Contextual Variables as Treatment Mediators 31

Parent and Youth Variables as Treatment Mediators: A Lagged 32

Effect

Summary of Mediational Studies $\quad 33$

Conceptual and Methodological Issues in Mediation Evaluation 33

The Present Study

III. METHODOLOGY 37

$\begin{array}{ll}\text { Participants } & 37\end{array}$

$\begin{array}{ll}\text { Measures } & 38\end{array}$

Primary Outcome Measure $\quad 38$

$\begin{array}{ll}\text { Mediation Measures } & 39\end{array}$

$\begin{array}{ll}\text { Parent Mediator Variables } & 39\end{array}$

$\begin{array}{ll}\text { Peer Mediator Variables } & 40\end{array}$

$\begin{array}{ll}\text { Procedures } & 41\end{array}$

Treatment Conditions $\quad 42$

$\begin{array}{ll}\text { Therapists } & 47\end{array}$

$\begin{array}{ll}\text { Study Design } & 47\end{array}$

$\begin{array}{ll}\text { IV. RESULTS } & 49\end{array}$

Preliminary Analyses $\quad 49$

Baseline to Posttreatment Effects $\quad 51$

Structural Equation Modeling $\quad 52$ 
Youth Ratings of Appraisal of Parental Positive-Negative

Behaviors toward the Child

Parent Ratings of Appraisal of Positive-Negative Behaviors

toward Child

Youth Ratings of Appraisal of Conflict in the Parent-Youth

Dyadic

Parent Ratings of Appraisal of Conflict in the Parent-Youth

Dyadic Relationship

Youth Ratings of Parental Acceptance

Parent Ratings of Parental Acceptance

Youth Ratings of Parental Control

Parent Ratings of Parental Control

Youth Self-Ratings of Positive Friendships

60

$\begin{array}{ll}\text { Parent Ratings of Youth Positive Friendships } & 60\end{array}$

$\begin{array}{ll}\text { Youth Self-Ratings of Negative Friendships } & 61\end{array}$

$\begin{array}{ll}\text { Parent Ratings of Youth Negative Friendships } & 62\end{array}$

$\begin{array}{ll}\text { Youth Self-Ratings of Social Skills } & 62\end{array}$

Parent Ratings of Youth Social Skills 63

$\begin{array}{lll}\text { V. DISCUSSION } & 64\end{array}$

Summary of Dissertation Findings $\quad 64$

Contribution of the Present Study and Implications 67

Limitations and Future Research Directions 69

LIST OF REFERENCES $\quad 84$

$\begin{array}{ll}\text { VITA } & 95\end{array}$ 


\section{LIST OF TABLES}

TABLES

PAGE

1. Demographic and Diagnostic Information

2. Mean (Standard Deviations) for Child Symptom Variables and

Mediating Variables at Baseline and Posttreatment

3. Fit Indices for Major Analyses Using Structural Equation Modeling

4. Selected Contemporaneous Path Coefficients for Youth Rated

76 Measures

5. Selected Contemporaneous Path Coefficients for Parent Rated Measures

6. Selected Autoregressive Path Coefficients for Youth Rated Measures

7. Selected Autoregressive Path Coefficients for Parent Rated Measures

8. Selected Lagged Path Coefficients for Youth and Rated Measures

9. Selected Lagged Path Coefficients for Parent Rated Measures 


\section{CHAPTER 1}

\section{INTRODUCTION}

Anxiety disorders are among the most prevalent disorders in child and adolescent psychopathology (Bernstein \& Borchardt, 1991; Costello \& Angold, 1995). Empirical evidence indicates that a significant proportion of anxiety disorders in young people do not dissipate over time, but may demonstrate moderate stability (Gullone, King, \& Ollendick, 2001), follow a chronic course that may last into adulthood (Last, Perrin, Hersen, \& Kazdin, 1996), and may lead to other disorders (e.g., other anxiety disorders, depression, substance abuse/dependence) (Last et al., 1996; Pine, Cohen, Gurley, Brook, \& Ma, 1998). Epidemiology studies report lifetime prevalence estimates of an anxiety disorder in children or adolescents range from about $15 \%$ to $20 \%$, with higher rates in females than males (Beesdo, Knappe, Pine, 2009; Wittchen, Nelson, \& Lachner, 1998). Hereafter children and adolescents are referred to as "youth." Cognitive Behavioral Treatment for Reducing Anxiety Disorders

In the last fifteen years, major advancements have been made in the treating anxiety disorders of youth. A plethora of empirical evidence has demonstrated that anxiety disorders in youth can be significantly reduced through cognitive behavioral treatment (CBT) (Barrett, 1998; Barrett, Dadds, \& Rapee, 1996; Kendall, 1994;

Silverman, Kurtines, Ginsburg, Weems, Lumpkin, \& Hicks-Carmichael, 1999a; Silverman, Kurtines, Jaccard, \& Pina, 2009). Several reviews have further concluded that CBT is effective using either an individual or individual plus parent involvement approach, with neither approach superior over the other (Barmish \& Kendall, 2005; Silverman, Pina, \& Viswesvaran, 2008). Given that over thirty clinical trials have 
demonstrated that youth anxiety disorders can be significantly reduced using CBT, CBT has been identified as an "empirically supported treatment" for anxiety disorders (Chambless \& Hollon, 1998; Silverman et al., 2008).

Relatively little is known, in contrast, about the mechanisms through which CBT leads to positive treatment response. There has been a recent push in psychotherapy research to go beyond determining whether treatment works, to examining why or how treatment works (Hinshaw, 2007; Kazdin, 2007; Kraemer, Wilson, Fairburn, \& Agras, 2002; La Greca, Silverman, \& Lochman, 2009).

\section{Mediators and Mechanism of Therapeutic Change}

It is important to first delineate distinctions between mechanisms and mediators . A mechanism of change refers to the process that leads to therapeutic change (Kazdin, 2007). A mechanism explains how the intervention translates into processes that result in a change in the outcome (Kazdin, 2007). A mediator is most commonly the variable used to signify a mechanism of change (Kazdin \& Nock, 2003). A mediator is an intervening construct that accounts for the relation between the intervention and the outcome (Kazdin, 2007). Thus, mediation occurs when treatment causes a change in a mediating variable, which in turn causes the dependent variable to change (i.e., significant positive change in child treatment outcome) (Baron \& Kenny, 1986; MacKinnon, Lockwood, Hoffman, West, \& Sheets, 2002). Although mediators can identify possible mechanisms, not all mediators are mechanisms (Kraemer et. al, 2002). Establishing mediation is the first step however in understanding the mechanism operating between a treatment and outcome(s) (Kraemer et al., 2002). 
Why Study Mediation?

The study of mediators is important for several reasons. Elaborating on mediators of change allows clinicians and researchers to zero in on key components of therapy needed to optimize therapeutic change (Kazdin, 2007; 2008; Kazdin \& Nock, 2003). This is especially important when extending treatments that have been found to be efficacious in research settings to real world community settings (Kadzin, 2008; Kadzin \& Nock, 2003). When transferring treatments from research settings to real world settings, it is important to apply those specific components and optimal conditions that are necessary to achieve therapeutic change (Kadzin, 2008). This allows the clinician with flexibility in treatment delivery and confidence that the most critical components necessary for successful treatment are being delivered (Kadzin, 2008; Kadzin \& Nock, 2003). In addition to advancing understanding about the mechanism of treatment outcome, identifying mediators may improve treatment outcome for youth with anxiety disorders who fail to demonstrate positive treatment outcome (i.e., approximately 30 40\%) (Kendall, 1994; Kendall, Flannery-Schroeder, Panichelli-Mindel, Southam-Gerow, Henin, \& Warman, 1997).

Testing for Mediation: The Exception Rather Than the Rule

In Weersing and Weisz's (2002) review of 67 youth clinical trials, only six trials tested for mediation (Eddy \& Chamberlain, 2000; Huey et al., 2000; Guerra \& Slaby, 1990; Patterson \& Forgatch, 1995; Treadwell \& Kendall, 1996; Kolko Brent, Baughter, Bridge, \& Birmaher, 2000). Of the six trials, one clinical trial for anxiety were identified that tested for mediation (i.e. Treadwell \& Kendall, 1996). Weersing and Weisz (2002) 
further noted that of the youth anxiety clinical trials included in their review, $30 \%$ included measures of potential mediators, but did not statistically test for mediation.

There continues to be limited information on mediation in child and adolescent anxiety treatments. Only four studies have been conducted to date: two evaluated individual child focused cognitive variables as potential mediators (Kendall \& Treadwell, 2007; Treadwell \& Kendall, 1997); one evaluated peer variables (Alfano, Pina, Villalta, Beidel, Ammerman, \& Crosby, 2009); and one evaluated parent variables (Silverman et al., 2009). These studies represent important initial efforts to examine mediation in treatment outcome research of childhood anxiety disorders. Nevertheless, they each contain several methodological limitations that will be further discussed in this dissertation.

A primary aim of this dissertation study is to evaluate whether variables that have been found to influence treatment outcome (i.e., parent behaviors, parent-youth relationship, child social skills, peer-child relationship) serve as potential mediators of a child and adolescent CBT anxiety program at multiple time points throughout treatment. Evaluating these potential mediators of treatment outcome not only represents an important contribution to a limited research literature, but also will represent an empirical test of a theoretical model that aims to advance understanding of how positive outcome may be produced in youth anxiety CBTs.

\section{Mediators of Treatment Outcome in CBT for Youth Anxiety Disorders}

CBTs for youth with anxiety disorders often have included parent involvement with components that target a variety of parent skills/variables. Research indicates that parents of children with anxiety disorders have a tendency to intrude or limit the 
autonomy of their children by taking over tasks that their children could be performing independently (Chorpita \& Barlow, 1998; Wood, Piacentini, Southam-Gerow, Chu, \& Sigman, 2006). Parents of youth with anxiety disorders also have been found to be controlling and lacking acceptance (Bernstein \& Garfinkel, 1988; Siqueland, Kendall, \& Steinberg, 1996; Whaley, Pinto, \& Sigman, 1999). For example, Bernstein and Garfinkel (1988) found that parents of children with anxiety disorders scored in the clinical range on dimensions of Communication, Affective Expression, and Control when compared to matched psychiatric controls. Siqueland et al. (1996) found parents of children with anxiety disorders were rated by observers as less granting of psychological autonomy than controls. They also found that children with anxiety disorders rated their mothers and fathers as less accepting than control children. Given this line of research, CBT for anxiety disorders in youth that includes parents have often targeted parent- youth relationships, focusing specifically on training parents in autonomy granting and acceptance.

Another parent variable that has been found to be linked to child anxiety is the parent-youth relationship. Numerous studies have found that youth with anxiety disorders have parent-youth relationships that are characterized as negative and lacking appropriate communication and problem solving skills (e.g., Ginsburg, Silverman, \& Kurtines, 1996; Rapee, 1997; Silverman, Cerny, \& Nelles, 1988). For example, Hudson and Rapee (2005) found that parents of anxious youth tend to engage in negative and critical behaviors towards them. Wood et al. (2006) found that youth with anxiety disorders tend to experience parent-youth conflict. Similar findings were reported by other studies (e.g., Bernstein \& Garfinkel, 1986, 1988; Last \& Strauss, 1990). 
In terms of social skills, youth with anxiety disorders have been found to have less social skills when compared to youth without anxiety disorders (e.g., Beidel, Turner, \& Morris, 1999; Spence, Donovan, \& Brechman-Toussaint, 1999; Strauss, Lease, Kazdin, Dulcan, \& Last, 1989; Verduin \& Kendall, 2008). For example, Strauss et al. (1989) reported that referred youth ( $n=55 ; 5$ to 17 years) who met now-outdated DSMIII diagnoses for separation anxiety disorder (SAD), overanxious disorder (OAD), both $\mathrm{SAD}$ and $\mathrm{OAD}$, or simple phobia $(\mathrm{SP})$ rated themselves, and were rated by their parents, as having significantly less social skills than a non-referred comparison control condition $(n=20)$.

In terms of peer-youth relationships, research indicates that problematic peer relationships are associated with negative mental health outcomes in youth (Parker \& Asher, 1987). For example, research indicates that youth who are isolated and rejected by their peers report high rates of internalizing problems such as depression, anxiety, and loneliness (e.g., La Greca \& Stone, 1993; Strauss, Lahey, Frick, Frame, \& Hynd (1988). Kingery, Erdley, Marshall, Whitaker, and Reuter (2010) recently reviewed a large number of studies on the peer experiences of youth with anxiety and social withdrawal problems. Studies' findings are consistent in showing that youth with anxiety disorders are less well liked and accepted by peers, have no or few friends, and are typically not involved in extracurricular activities with peers compared to non-clinic referred youth and/or referred youth with other psychological disorders (Beidel et al., 1999; Chansky \& Kendall, 1997; Strauss et al., 1998; Strauss et al., 1989; Verduin \& Kendall, 2008).

A primary aim of this dissertation is to evaluate whether parent behaviors, parentyouth relationship, child social skills, and peer-child relationship serve as mediators of a 
child and adolescent CBT anxiety program at multiple time points throughout treatment. These variables were selected for investigation in light of the evidence review above indicting their relations to youth anxiety. Evaluating these variables as potential mediators also will serve to empirically test a theoretical model that aims to advance understanding of how positive outcome may be produced in youth anxiety CBTs.

\section{Cross-sectional vs Longitudinal Data to Test Mediation}

The formulations and associated statistical tests for demonstrating mediation (e.g., Baron and Kenny approach, Sobel Test, Joint-Significance Test) have been useful and influential to researchers who study meditational models (Baron \& Kenny, 1986; MacKinnon et al., 2002). Often times, cross-sectional data are used to test meditation (Maxwell \& Cole, 2007). However, there are a number of fundamental problems with using cross-sectional data to test meditational models (e.g., bias estimation, left out variable error, lag) (Gollob \& Reichardt, 1987; 1991; Kadzin, 2007; Weersing \&Weisz, 2002). Utilizing longitudinal data to test meditational models therefore have several advantages over cross-sectional data (Maxwell \& Cole, 2007). One major advantage is that it allows the researcher to examine the critical role of time. This includes examining what are the optimal time lags from one part of the meditational model (e.g., mediating variable measured at sessions $2,4,6$ ), to another part of the same model (e.g., mediating variable measured at sessions $8,10,12$, post,) necessary for mediation to occur.

In the child and adolescent treatment research, in general, including anxiety disorders, there are no theoretical or empirical explanations regarding the appropriate time lags necessary for mediation to occur. Since the effect(s) of the mediating variable(s) on the outcome may not be instantaneous, but may take time (Jaccard \& 
Jacoby, 2010) it is important to determine the choice of time interval. For example, a treatment that targets parenting skills will train parents to deal with their child's anxiety. If the parent skill is acquired, the effect of the recently acquired parent skill on the child's anxiety may not be instantaneous. Instead, it may take time for the parent to apply the skill and for the effects of the newly acquired skill to translate into reduced youth anxiety (Jaccard \& Jacoby, 2010). This dissertation sought to examine this issue by investigating the mediating variables measured at multiple time points throughout treatment (i.e., sessions $4,8,6,10,12$, and posttreatment). This examination will help to determine the time lags necessary for changes in the mediator variable to translate into changes in the outcome on treatment gains. Collecting data on the mediator and the outcome at multiple time points allows for statistical controls for prior levels of the dependent variables using structural equation modeling (SEM) (Cole \& Maxwell, 2003).

This dissertation is organized as followed. The dissertation begins with a review of the randomized clinical trials conducted for youth with anxiety disorders, followed by an overview of the studies that examined mediation. Next, is a discussion of the fundamental issues in testing meditational models. This includes a discussion of the theory of change for variables in the model, the role of time in the model, and the types of indirect effects in the model. The next section discusses the dissertation's methodology to address the study's research questions. This is followed by a presentation of the dissertation findings and a discussion of these findings including their theoretical and applied significance. 


\section{CHAPTER II}

\section{LITERATURE REVIEW}

Strong and consistent empirical evidence has accumulated documenting that CBT used in several formats (e.g., individual, group, parent involvement) are more efficacious than a waitlist control condition in reducing anxiety disorders in youth. The following section reviews the randomized clinical trials that have been conducted in these various formats and their findings.

Psychosocial Interventions for Childhood Anxiety Disorders

Parental Involvement in Child Anxiety Treatment

The treatment studies that involved parents are summarized in this section. Unless otherwise indicated, all parent ratings were mainly completed by mothers. As noted early, reviews have concluded that CBT is efficacious when involving parents (e.g., Barrett, 1998; Barrett et al., 1996; Kendall \& Treadwell, 2007; Silverman et al., 2009; Wood et al., 2006) and peers (e.g. Beidel, Turner, \& Morris, 2000; FlannerySchroeder \& Kendall, 2000; Hayward, Varardy, Albano, Thienemann, Henderson, \& Schatzberg, 2000; Silverman et al., 1999a; Spence, Donovan, and Brechman-Toussaint, 2000). In parent-involvement treatment studies, the mother is typically the parent included in the treatment. Procedures in CBTs that incorporate parents usually include teaching parents reinforcement strategies of the youth's anxious avoidant behaviors (e.g., Barrett, 1998; Barrett et al., 1996) and improving parents' parenting behaviors and the parent-youth relationship (e.g., Barrett, 1998; Barrett et al., 1996; Silverman et al., 2009). In Barrett et al. (1996), parenting skills (i.e., parents were trained in reinforcement skills) and other parenting variables (i.e., communication and problem solving skills) 
were included in an Individual CBT (ICBT) with Parents condition. In this study, 79 youth (ages 7 to 14 years; $M$ and $S D$ were not reported) with anxiety disorder diagnoses were randomized to an ICBT condition, ICBT with Parents condition, or a waitlist. Findings indicated that at posttreatment, $68 \%$ of the youth across the two treatment conditions no longer met diagnostic criteria for an anxiety disorder, in comparison to the $26 \%$ in the waitlist condition. Further, both treatment conditions demonstrated significantly more pre to posttreatment improvement than the waitlist on the Fear Survey Schedule for Children - Revised (FSSC-R; Ollendick, 1983), the Children's Depression Inventory (CDI; Kovacs, 1992), mothers' and fathers' ratings on the Child Behavior Checklist - Internalizing scale (CBCL-I; Achenbach, 1991) and Child Behavior Checklist - Externalizing scale (CBCL-E; Achenbach, 1991), and behavior observations.

When the ICBT condition was compared to the ICBT with Parents condition, statistically significant differences were found on diagnostic recovery rates $(57.1 \%$ vs. $84 \%$, respectively). In addition, treatment gains were maintained for both conditions at 1 year follow-up, with ICBT with Parents condition demonstrating statistically significantly superior diagnostic recovery rates than the ICBT condition.

A 6 year follow-up study by Barrett, Duffy, \& Dadds (2001) was conducted on 52 of the 79 children (ages 13 to 21 years; $M=16.1$ years; $S D=2.3$ ). Treatment gains were maintained for anxiety symptoms and anxiety related impairment based on clinician ratings, and parent and child ratings with no significant differences between conditions. Barrett (1998) also targeted parenting skills in a study that sampled 60 youth (ages 7 to 14 years; $M$ and $S D$ were not reported) with primary anxiety diagnoses. Youth were randomized into three conditions; group CBT (GCBT) $(n=23)$, GCBT with Parents 
$[(\mathrm{n}=17$; also referred as GCBT plus Family Anxiety Management (FAM)], or a waitlist control condition $(n=20)$. In GCBT plus FAM, children received CBT, while their parents received training in parenting skills (i.e., interacting with their child when the child is displaying anxiety, managing child emotional upsets, communication and problem solving skills).

Findings indicated that at posttreatment, $64 \%$ of the youth in the two GCBT conditions no longer met diagnostic criteria for their primary targeted diagnoses, as compared to $25.3 \%$ in the waitlist control condition. Significant changes were found from pretreatment to posttreatment for the two GCBT conditions when compared to the waitlist control condition on youths' rating on the FSSC-R, mothers' and fathers' CBCLI/E ratings, and clinicians' ratings of diagnostic severity. When the GCBT condition was compared to the ICBT with Parents condition, no significant differences were found in diagnostic recovery rates $(55.9 \%$ and $70.7 \%$, respectively), and on mothers' and fathers' pre- to posttreatment CBCL-I/E ratings. GCBT with Parents demonstrated statistically significant improvement over GCBT on clinicians' ratings of severity and youths' FSSC$\mathrm{R}$ ratings. Treatment gains were maintained for both GCBT conditions at 1 year followup, with GCBT with Parents continuing to demonstrate significantly greater improvements than GCBT on diagnostic severity ratings and FSSC-R ratings.

In 67 youth (ages 7 to 14 years; $M=9.6$ years, $S D=1.8$ ) with anxiety disorders, Cobham, Dadds, and Spence (1998) targeted parental anxiety when treating youth with anxiety disorders. Both mothers and fathers were randomized to either a GCBT condition $(n=32)$ or a GCBT plus Parental Anxiety Management condition (GCBT plus PAM, $n=35$ ). Parental anxiety was measured using the adult State-Trait Anxiety 
Inventory (STAI; Spielberger \& Gorsuch, 1970). Based on parental anxiety levels as measured by the STAI, parents were classified as either non-anxious or anxious. Participants in both GCBT and GCBT plus PAM conditions received cognitive behavioral therapy, with GCBT plus PAM including a parental anxiety management component.

Findings indicate that amongst youth whose parents were classified non-anxious, no statistically significant differences in diagnostic recovery rates for youth were found between GCBT (82\%) and GCBT with PAM (80\%). Amongst youth whose parents were classified as anxious, statistically significant differences were found between GCBT and GCBT plus PAM: $39 \%$ in GCBT and $77 \%$ in GCBT plus PAM no longer met criteria for an anxiety disorder. Cobham et al. (1998) suggest that this significant difference may have been biased by the clinicians' expectancies for improvement because the clinicians were not blind to participants' assigned condition. Additionally, both conditions demonstrated significant improvement from pre to posttreatment in youth self ratings of anxiety using the Revised Children's Manifest Anxiety Scale (RCMAS; Reynolds \& Richmond, 1978) and State-Trait Anxiety Inventory for Children-Trait Version (STAICT; Spielberger, 1973). All treatment gains (i.e., diagnostic recovery rates, youth self ratings, clinician ratings) were maintained at 6 and 12-month follow-up, with no significant differences between GCBT and GCBT plus PAM.

In Mendlowitz, Manassis, Bradley, Scapillato, Miezitis, and Shaw (1999), 62 children (ages 7 to 12 years; $M=9.8 ; S D$ not reported) who met diagnostic criteria for an anxiety disorder were randomized to GCBT (i.e., child only participated in treatment, $n=$ $23)$, GCBT with parent $(n=18)$, or GCBT parent only $(n=21)$. Participants were 
assigned to a waitlist control condition if they waited 2 to 6 months before beginning treatment (59\% of total sample). Forty (65\%) of the 62 participants were assigned to a waitlist control condition prior to randomization.

The Coping Bear Workbook (Scapillato \& Mendlowitz, unpublished,1993), an adaptation of Kendall's (1990) Coping Cat Workbook, was used to teach children how to identify somatic symptoms when they are feeling anxious, how to modify their anxious self-talk into coping self-talk, how to evaluate and reinforce their own coping efforts, and the use of physical relaxation. Keys to Parenting Your Anxious Child (Manassis, 1996) was used in the GCBT with parent and the GCBT parent only all conditions to help parents to understand anxiety, learn how to handle more effectively their anxious child, and learn how to help their anxious child cope with fearful situations.

Children completed the RCMAS, CDI, and parents and children completed the Global Improvement Scale (National Institutes of Health, 1985). Children in the GCBT with Parent condition were found to use more active coping strategies at posttreatment on the CCSC and parents reported significantly greater improvement in their children's emotional well-being compared to the children in the other two conditions. All three treatment conditions reported fewer symptoms of anxiety on the RCMAS and fewer symptoms of depression on the CDI at posttreatment, with no significant differences between the three conditions. The waitlist demonstrated no improvements on any measure.

A 6 to 7 year follow-up study by Manassis, Avery, Butalia, and Mendlowitz (2004) was conducted on 43 of the 62 children (age range not reported, $M=16.5$ years; $S D=1.2)$. The now adolescents and their parents were contacted by telephone and asked 
questions about clinically relevant anxiety symptoms. Treatment gains were generally maintained for anxiety symptoms. Adolescents reported being bothered by 1.73 anxiety symptoms on average and parents reported their adolescents being bothered by 1.84 anxiety symptoms on average.

In Silverman et al. (1999a), 104 youths (ages 6 to 16 years; $M=9.86$ years) who met diagnostic criteria for a phobic disorder were randomized to an exposure plus selfcontrol condition (SC; $n=41$ ), exposure plus contingency management condition (CM; $n$ $=40$ ) condition, or an education support condition (ES; $n=23$ ). In SC, the cognitive components of CBT were emphasized and youth were trained in self-observation, selftalk, self-evaluation, and self-reward. In CM, the behavioral components of CBT were emphasized and parents were trained in positive reinforcement strategies, shaping, extinction, and contingency contracting.

Findings indicated that all three treatment conditions demonstrated statistically significant pre to posttreatment improvements on youth- and parent-completed RCMAS and FSSC-R, and youth-completed CDI. No significant differences were found on any of the measures across the three conditions. The only exception were statistically significant differences from pre to posttreatment for diagnostic recovery rate of primary targeted diagnoses, with the rate in SC significantly lower than the rate in CM ( $88 \%$ for SC; $56 \%$ for CM; 76\% for ES). Silverman et al. (1999a) suggested that youth in the ES condition may have demonstrated improvement because they may have engaged in self-directed exposures (Last, Hansen, \& Franco, 1998). The authors concluded that graded in vivo and imaginary exposures combined with SM or SC procedures are both efficacious and can be used concurrently with exposure tasks to reduce phobias. Follow-up $(3,6$, and 12 
months) assessments revealed that gains were maintained on the youth and parent measures, again with no significant differences across the three conditions.

In a study by Silverman, Kurtines, Ginsburg, Weems, Rabian, Serafina (1999b) 56 youths (ages 6 to 16 years; $M=9.96$ years, SD not reported) who met diagnostic criteria for SOP $(n=15)$ and OAD $(n=41)$ were randomized to a GCBT with parents (n $=37)$ or waitlist control condition $(n=19)$. Findings indicate that at posttreatment, $64 \%$ of youth in GCBT no longer met primary diagnosis compared to $12.5 \%$ in the waitlist. Statistically significant improvements were observed pre- to posttreatment for treated but not waitlisted youth on clinicians' ratings of diagnostic severity, youth self-ratings on the RCMAS, FSSC-R, and CDI, and parent CBCL-I/E ratings. Continued improvement were observed on all rating scales from posttreatment to 3-month follow-up, with continued maintenance of treatment gains over 6- and 12-month follow-up.

A long term follow-up (LTFU) study was conducted by Saavedra, Silverman, Morgan-Lopez, and Kurtines (2010) of participants who participated in the Silverman et al. (1999a) and (1999b) study. At LTFU, there were 67 youth (ages 16 to 26 years; $M=$ 10.27 years; $S D=1.71)$. LTFU youth who were 18 years or older completed the parallel adult versions of the measures completed at pre and post [(i.e., Young Adult Self Report (YASR; Achenbach, 1997), Taylor Manifest Anxiety Scale (MAS; Taylor, 1953), Children's Depression Inventory (CDI; Kovacs, 1981)].

Findings indicate significant decreases in anxiety, depression, and internalizing symptoms among participants in GCBT from posttest through 1-year follow-up. Differences in decreases in anxiety, internalizing, and depression symptoms for participants in GCBT from 1-year follow-up through LTFU were nonsignificant. No 
differences were found on decreases in anxiety symptoms over time from post-test through 1-year follow-up between participants in GCBT and ICBT conditions. Static levels of depression at LTFU were significantly lower for ICBT conditions compared to GCBT. Authors note that these differences may likely be due to existing differences at pre-test. Participants in the ICBT conditions demonstrated steeper reductions in internalizing symptoms from pre-test to post-test compared to GCBT.

Diagnostic recovery rates were $92.5 \%$ for targeted anxiety disorder, $86.5 \%$ for any anxiety disorder, $95.5 \%$ for DSM-IV major depression, and $82.1 \%$ for any new DSM-IV psychiatric disorders. In terms of primary and secondary diagnostic status, no statistically significant differences were found between the three conditions.

Bögel and Siqueland (2006) included parenting skills (i.e., parents' identification of parents or child negative thoughts, in vivo exposures, and rewards) along with other parenting skills (i.e., modification of children's and parents' dysfunctional beliefs, communication and problem solving skills) in an open trial of family CBT (FCBT). Twenty four youth (ages 8 to 17 years; $M=12.7$ years; $S D=2.1$ ) with primary anxiety diagnoses were participants along with their parents. Because this was an open trial, participants were not randomly assigned to condition. Instead, participants who were waiting to be treated due to unavailable therapists served as a waitlist condition.

At posttreatment, $46 \%$ of participants in FCBT no longer met diagnostic criteria for their primary targeted diagnoses. Statistically significant changes were found from pre to posttreatment on youth, mother, and father ratings on the Screen for Child Anxiety Related Emotional Disorders (SCARED; Birmaher, Khetarpal, Brent, Cully, Balach, 
Kaufman, 1997) and mother CBCL-I/E ratings. These gains were maintained at 3 and 12 month follow-up.

Wood et al. (2006) compared the efficacy of FCBT and ICBT $(\mathrm{N}=38$ youth; (ages 6 to 13 years; $M=9.83$ years, $S D=2.19$ ) with primary anxiety diagnoses. The primary parent (defined as the parent who was primarily responsible for overseeing the youth's daily activities) participated in the FCBT condition. FCBT focused on changing parental communication patterns, particularly intrusiveness and autonomy granting. At posttreatment, $52 \%$ of the youth in ICBT and 78\% in FCBT no longer met diagnoses for an anxiety disorder. Posttreatment diagnostic recovery rates were $78.9 \%$ for FCBT and $52.6 \%$ for ICBT, a non-significant difference. Based on clinicians' ratings, $78 \%$ of participants in FCBT and $26.3 \%$ in ICBT were rated by clinicians as "completely recovered or very much better."

The comparative efficacy of a FCBT and a group-family focused (G-FCBT) was evaluated by De Groot, Cobham, Leon, and McDermott (2007). The sample included 29 youth (ages 7 to 12 years; $M=8.86$ years; $S D$ not reported). FCBT in this study focused on teaching parents in how to manage their own anxiety symptoms and how to model appropriate anxiety management to their children. Additional components of FCBT included teaching parents to reinforce their child's brave behavior through cognitive restructuring, relaxation training, exposures, and problem solving skills.

Findings indicated that $57 \%$ of youth in FCBT and $47 \%$ in G-FCBT no longer met diagnostic criteria for an anxiety disorder at posttreatment, a non-significant difference. Significant improvement from pre to posttreatment was demonstrated on children's ratings on the Spence Children's Anxiety Scale (SCAS; Spence, 1998) and 
parents' ratings on the Total Emotional subscale of the Strengths and Difficulties Questionnaire, (SDQ; Goodman, 1997, 1999). Three month follow-up indicated no significant change in severity ratings for children's primary diagnoses, with no significant differences between treatment conditions. Six month follow-up revealed diagnostic recovery rates of $50 \%$ for $\mathrm{FCBT}$ and $53 \%$ for G-FCBT, a continued lack of significant difference in diagnostic recovery rates.

In a sample of 128 youth ( 8 to 17 years; $M=12.4$ years; $S D=2.7$ ) referred to community mental health centers, Bodden, Bögels, Nauta, De Hann, Ringrose, Appelboom, Brinkman, and Appelboom-Gerts, (2008) examined the efficacy and partial effectiveness of ICBT $(n=64)$ and FCBT $(n=64)$. Authors refer to this study as a partial effectiveness trial because children were clinically referred, nonrecruited youths and treatments were performed by practicing representative clinicians in clinical care settings. Families were first randomly assigned to either a treatment $(\mathrm{n}=109)$ or an 8 - to 12-week waitlist condition. Of the waitlisted families, 19 were again randomized to treatment. Families that were randomly assigned to treatment were ultimately randomly assigned to either ICBT $(n=64)$ or FCBT $(n=64)$. Twenty-five of the 128 participants were measured before and after a 2- to 3-month waitlist period. Both parents were participants in the study (91\% fathers; $98 \%$ mothers). FCBT targeted parenting skills relating to autonomy granting, communication, and modeling of nonanxious behavior, as well as the targeting of parental anxiety. ICBT focused on cognitive and behavioral components of CBT, as well as psychoeducation. Measures included the SCARED and the STAI completed by both parents and youth; the CBCL completed by the parent, and 
the Children's Automatic Thought Scale (CATS; Schniering \& Rapee, 2002) completed by the youth.

Statistically significant differences were found at posttreatment on all the outcome measures (e.g., SCARED, STAI, CATS, and CBCL-I) and diagnostic recovery rates, with ICBT statistically superior over FCBT (53\% in ICBT; $28 \%$ in FCBT). However, at 3month follow-up, no significant differences were found between FCBT and ICBT on diagnostic recovery rates or on the questionnaires completed by the youth and parent. Fifty-two percent of youth across both conditions maintained treatment gains at 3 month follow-up assessment. Findings indicated that all the waitlist participants still met diagnostic criteria for an anxiety disorder after the 3 month waitlist period.

Kendall et al. (2008) examined the relative efficacy of ICBT $(n=55), \operatorname{FCBT}(n=$ 56), and family-based education/support/attention (FESA; $n=50$ ) in a sample of 161 youth (ages 7 to 14 years; $M=10.27$ years; $S D$ not reported) diagnosed with an anxiety disorder. In ICBT, youth were taught skills to manage their anxiety (e.g., recognizing anxious feelings and cognitions, developing a plan to cope with anxiety provoking situations) and behavioral strategies (e.g., modeling, imaginal and in-vivo exposure tasks, role play, relaxation). In addition to teaching youth skills to manage anxiety and behavioral strategies, parents in FCBT were taught a variety of parenting skills (i.e., changing maladaptive parental beliefs and expectations, constructive responses to their child's anxious distress, effective communication). In the FESA condition, youth and their parents were provided with psychoeducation regarding anxiety. No prescriptions were made regarding exposures and other CBT procedures. 
Treatment gains were found on the MASC and Coping Questionnaire for Children (CQ-C; Kendall \& Marrs-Garcia, 1999) and mother-reported CBCL-I, anxiety symptoms (CBCL-A), and coping (CQ-P). Diagnostic recovery rates for primary anxiety diagnoses were $64 \%, 64 \%$, and $42 \%$ for ICBT, FCBT and FESA, respectively. FCBT and ICBT demonstrated significantly greater diagnostic recovery rates than FESA. The only measure that ICBT demonstrated greater reductions than FCBT and FESA was on teacher ratings of child anxiety symptoms. Findings also indicated that at 12 month follow-up, principal diagnoses were no longer principal disorders for $67 \%$ in ICBT, $64 \%$ in FCBT, and $46 \%$ in FESA. Sixty one percent of youth in ICBT, $58 \%$ of youth in FCBT, and $44 \%$ of youth in FESA no longer met diagnostic criteria for principal anxiety diagnoses at one year follow-up. Significant improvements were found from pre to follow-up, and post to follow-up on the MASC and CQ-Q and mother-reported CBCL-I, CBCL-A, and CQ-P. No significant differences were found between the three conditions between pre and follow-up or between post and follow-up for any of the three conditions.

\section{Parent and Peer Childhood Anxiety Group Treatment}

This section reviews treatment studies that were administered in a group format for the child and/or parent, and that included parenting training, social skills training, or both.

Silverman, Kurtines, Ginsburg, Weems, Lumpkin, et al. (1999) randomized 56 youth (6 to 16 years; $M=9.96$ years) with primary anxiety diagnoses of SOP, overanxious disorder (OAD), or generalized anxiety disorder (GAD) to either GCBT with Parents $(n=37)$ or a waitlist $(n=19)$. Youth and parents were seen in separate youth and parent groups. In GCBT, treatment included peer modeling, feedback, support, 
reinforcement, and social comparison. At posttreament, $64 \%$ of youth in GCBT with Parents condition no longer met their primary diagnoses compared to $12.5 \%$ in the waitlist condition. Youth in GCBT condition also demonstrated statistically significant pre- to posttreatment improvements on clinicians' ratings of diagnostic severity, youths' self-ratings on the RCMAS, FSSC-R, and CDI, and parents' CBCL-I/E ratings. No improvements were found in the waitlist condition. Continued maintenance of treatment gains were found on all rating scales over 3, 6, and 12 month follow-up.

Shortt, Barrett, and Fox (2001) randomized 71 youth (6 to10 years, $M=7.85$ years, $S D$ ) with anxiety diagnoses and their parents to either the FRIENDS program condition, which is a family based GCBT $(n=54)$, or a waitlist $(n=17)$. In the FRIENDS program, the focus was on increasing children's and parents' social support networks. Findings indicate that diagnostic recovery rates for participants in FRIENDS $(69 \%)$ were statistically significantly greater than for participants in the waitlist condition (6\%). There also were statistically significant pre to posttreatment improvements on the RCMAS and mother CBCL-I ratings (not father) for youth in the FRIENDS program condition, but not for youth in the waitlist condition. Twelve month follow-up revealed that treatment gains were maintained on all these rating scales.

Manassis, Mendlowitz, Scapillato, Avery, Fiksenbaum, and Freire (2002) randomized 78 children ( 8 to 12 years; $M=9.98$ years, $S D=1.25$ ) with primary anxiety diagnoses to either ICBT $(n=41)$ or GCBT $(n=37)$. Parents were involved in both treatment conditions and received the same treatment components. Parents worked with the Keys to Parenting Your Anxious Child book (Manassis, 1996), described earlier. Children completed the Coping Bear Workbook, also described earlier. Statistically 
significant pre to posttreatment improvements were found for both treatment conditions on children's ratings on the Social Anxiety Scale for Children (SASC) (La Greca \& Stone, 1993), Multidimensional Anxiety Scale for Children (MASC; March, Parker, Sullivan, Stallings, \& Conners, 1997), and CDI and clinicians' ratings on the Children's Global Assessment Scale (CGAS; Endicott, Spitzer, Fleiss, \& Cohen, 1976). ICBT demonstrated significantly greater improvement than GCBT on the CDI and CGAS. Diagnostic recovery rates and follow-up data were not reported in the article. Findings also indicated that children reporting high social anxiety on the SASC also reported greater gains in individual treatment than in group treatment. Manassis et al. (2002) suggest that superior ICBT performance on these measures may have been due to more direct reassurance and social approval from GCBT therapists, as GCBT may have been overwhelming initially for children with social evaluative concerns.

Rapee, Abbott, and Lyneham (2006) randomized 267 children (6 to 12 years; $M$ and $S D$ were not reported for the total sample), with anxiety disorders to GCBT $(\mathrm{n}=90)$, bibliotherapy condition ( $\mathrm{n}=90)$, or a waitlist condition $(n=87)$. In the bibliotherapy condition, parents were instructed to conduct the treatment at home with the aid of a commercially available book. Children were supplied with a workbook containing similar information. Findings indicated that at posttreatment, $61.1 \%$ in GCBT, $25.9 \%$ of children in bibliotherapy, and $6.7 \%$ in the waitlist no longer met criteria for their primary diagnosis. At pre to posttreatment, statistically significant improvements on clinicians' ratings of diagnostic severity, children's ratings on the SCAS, and a measure of automatic thoughts, as well as parents' SCAS and CBCL-I/E ratings were found in the GCBT condition, but not the waitlist condition. Intent-to-treat analyses revealed that 
participants in bibliotherapy showed no improvement, similar to the findings reported for the waitlist condition. Three month follow-up data revealed that GCBT gains were maintained, and continued to demonstrate statistically significant gains over the bibliotherapy condition. These findings suggest that although bibliotherapy is better than no treatment, it is less efficacious than GCBT.

In Thienemann, Moore, Tompkins, Moore, and Tompkins (2006), 24 parents of youth (ages 7 to 16 years; $M=12.1$ years, $S D=2.4$ ) with anxiety disorders participated in an open trial Parent Group CBT. Parent Group CBT included psychoeducation (e.g., identifying normal and abnormal anxiety, teaching their children social skills, child management skills). Findings indicated that $25 \%$ of youth no longer met for their primary anxiety diagnosis and $54.9 \%$ of all anxiety disorder diagnoses remitted at posttreatment. Significant pre to posttreatment improvements were found on youths' MASC self-ratings, but only for youth whose mothers had anxiety disorders. Mother rated MASCs, mothers' attitudes toward their children, and clinicians' ratings of severity also demonstrated statistically significant pre to posttreatment improvements. Additional findings revealed that youth of mothers with anxiety disorders demonstrated significantly greater pre to posttreatment improvement on youth-rated MASCs than youth of mothers without anxiety disorders. These findings demonstrated a significant improvement in parental attitudes across treatment.

Peer Involvement in Child Anxiety Treatment

This next section focuses on treatment studies involving peers and that included a social skills or social competence skills training component. 
Beidel et al., (2000) compared the relative efficacy of Social Effectiveness Training for Children (SET-C; $n=30$ ) and Testbusters (the control condition; $n=20$ ) (ages 8 to 12 years; $M=10.5$ years; $S D=1.5$ ) for children who met for a primary diagnosis of social phobia (SOP). SET-C focused on providing child and parent education, social skills training, peer generalization experiences, and child in vivo exposure. Testbusters focused on providing training in study skills and test preparation. Findings indicated that $67 \%$ of youth in SET-C and 5\% in Testbusters no longer met diagnostic criteria for SOP. In SET-C pre to posttreatment gains were observed on children's ratings on the Eysenck Personality Inventory (Eysenck \& Eysenck, 1968), the Social Phobia and Anxiety Index (SPAI; Turner, Stanley, Beidel, \& Bond, 1989), parents' ratings on the CBCL-I, clinicians' C-GAS (C-Gas; Shaffer, Fisher, Gould, 1993) and diagnostic severity ratings, and child and observer ratings during a read aloud task. No significant improvements were found in the Testbuster condition. Pre to posttreatment gains were observed in both conditions on the STAIC-T and State-Trait Anxiety Inventory for Children-State Version (STAIC-S; Spielberger, 1973), the Loneliness Scale (Asher \& Wheeler, 1985), and on the child and observer ratings. The pre to posttreatment Testbuster gains perhaps were due to opportunities the child received to practice reading aloud and interacting with peers (Silverman et. al., 2008). Six month follow-up data revealed treatment gains were maintained for youth in the SET-C condition on all rating scales, with diagnostic recovery rates of $85 \%$. Follow-up data were not reported for the Testbuster condition.

Flannery-Schroeder and Kendall (2000) compared the relative efficacy of ICBT $(n=13)$, GCBT $(n=12)$, and a waitlist $(n=12)$ condition in a sample of 37 youth ( 8 to 
14 years; $M s$ and $S D s$ were not report) with anxiety disorders. No statistically significant differences were found on diagnostic recovery rate between ICBT and GCBT; but both treatments were significantly different than the waitlist condition (73\% in ICBT; $50 \%$ in GCBT; $8 \%$ in the waitlist). Youth in ICBT and GCBT demonstrated significant pre to posttreatment gains relative to the waitlist on the STAIC-T, RCMAS, CQ-C, CDI, Social Acceptance subscale of the Self Perception Profile for Children (Harter, 1985), and mother and father completed STAIC-T/P, CQ-P, and father completed CBCL-I. No statistically significant differences were found among the three conditions on the CBCL Social Activities subscale, the internalizing ratings of the teacher version of the CBCL [i.e., the Teacher Report Form (TRF; Achenbach \& Edelbrock, 1986)], and after a Bonferroni correction, mothers' CBCL-I ratings. The non-significant effect on the CBCL Social Activities Scale is reasonable since neither ICBT nor GCBT directly targeted social skills and only 5 of the 36 participants had a targeted diagnosis of SOP (FlannerySchroeder \& Kendall, 2000). Three month follow-up data revealed that gains in diagnostic recovery rates were maintained for both treatment conditions ( $79 \%$ in ICBT; $53 \%$ in GCBT), with continued nonsignificant differences between ICBT and GCBT. Hayward et al. (2000) evaluated the relative efficacy of GCBT $(n=12)$ to No Treatment $(n=23)$ in a sample of 35 adolescent females (age range not reported; $M=$ 15.8 years, $S D=1.6$ ) with a DSM-IV diagnoses of SOP. In terms of diagnostic recovery rates, a statistically significant difference was found with $45 \%$ of adolescents in GCBT no longer meeting diagnostic criteria for SOP compared to $4 \%$ in the No Treatment condition. Statistically significant improvements also were found pre to posttreatment for GCBT on the SPAI, and adolescent and parent SOP symptom ratings on the ADIS-IV: 
C/P. The No Treatment condition failed to demonstrate significant changes from baseline to 5 months on any measure. Twelve month follow-up data revealed that $40 \%$ in GCBT continued to meet diagnosis for SOP compared to $56 \%$ in the No Treatment condition. Moreover, $40 \%$ in GCBT met diagnostic criteria for either SOP or major depression relative to $78 \%$ in the no treatment condition. Hayward et al. (2000) indicate that it is unclear why GCBT demonstrated less robust effects in this study than in past studies. They suggest that perhaps the girls' heterosocial anxiety may have played a role, as it was not targeted in treatment. The authors further suggested that the SOP diagnoses may have been confounded with episodes of major depression.

In Spence et al. 2000, 50 youth diagnosed with SOP (ages 7 to 14 years; $M$ and $S D$ were not reported) were randomized to GCBT $(n=19)$, GCBT plus Parent Involvement $(n=17)$, or a waitlist $(n=14)$. The GCBT condition focused primarily on social skills training. In addition to social skills training, GCBT plus Parent Involvement trained parents in behavioral procedures (e.g., modeling, extinction, reinforcement).

Findings indicated that at posttreatment, significant differences were found on diagnostic recovery rates, with significantly lower rates in GCBT (58\%) and GCBT with parents (87.5\%), and even lower significant rates in the waitlist (7\%). Findings also indicated that statistically significant pre to posttreatment improvements were evident for the GCBT and GCBT plus Parent Involvement condition, but not the waitlist on the youth self-rated RCMAS, SCAS, and on measures of social worries, parent-rated youth social skills, social competence, and behavior observations. No significant pre to posttreatment and 6 and 12 month follow-up differences were evident between the two GCBT conditions on any measure. 
Gallagher, Rabian, and McCloskey (2004) randomized 23 children with SOP (8 to 11 years; $M$ and $S D$ were not reported for the total sample) to either a three-session GCBT condition $(n=12)$ or waitlist condition $(n=11)$. There were no statistically significant improvements from pre- to posttreatment in the GCBT condition. However, from pretreatment to 3-month follow-up, significant improvements were found for GCBT but not the waitlist on children's ratings on the Social Phobia and Anxiety Inventory for Children (SPAI-C; Turner, Biedel, \& Morris, 1995), Social Anxiety Scale for Children Revised (SASC-R; La Greca \& Stone, 1993), RCMAS, CDI, parents' anxious/depressed scale of the CBCL (CBCL-A/D), and clinicians' ratings of diagnostic severity. According to the authors, these treatment lagged effects may indicate that additional time intervals may be necessary for skills to translate into positive treatment effects since there were only three-sessions in the treatment condition.

Baer and Garland (2005) randomized 12 adolescents with SOP (13 to 18 years, $M$ $=15.5$ years, $S D$ were not reported for the total sample) to either a modified SET-C (i.e., "Cognitive Behavioral Group Therapy for Adolescents"; $n=6)$ or a waitlist $(n=6)$. At posttreatment, 4 participants (36\%) in modified SET-C no longer had their primary targeted SOP diagnosis compared to the waitlist condition, in which all adolescents continued to meet diagnostic criteria for SOP. Significant pre to posttreatment improvements also were evident for adolescents in the SET-C condition, but not in the waitlist condition on the SPAI-C and clinicians' ratings of diagnostic severity.

Baer and Garland (2005) note treatment efficacy for the modified SET-C was less evident for diagnostic recovery rates than in Beidel et al. (2000), perhaps because of the duration of the modified SET-C, which was 18 hours long versus 42 hours in Beidel et 
al. (2000). The authors further note that the modified SET-C excluded two treatment elements (i.e., peer generalization sessions and contingent reinforcement), which may be necessary components for successful treatment outcome.

\section{Summary of Treatment Studies}

Collectively, the studies demonstrate that CBT is efficacious in reducing youth anxiety disorders. What remains unknown is how the variables targeted in the above mentioned studies are linked empirically to treatment outcome (i.e., mediation). Although these studies included measures that assessed targeted variables, none of these studies tested for mediation.

Weersing and Weisz (2002) note that meditational analyses were not examined in many treatment studies for several reasons. One, the above studies were primarily conducted to investigate under what formats CBT is most efficacious. Two, to accurately test for mediation, the proposed mediating variables need to be identified before the research project. This is necessary to ensure adequate resources for data collection, to determine the time points to administer the measures, and to ascertain the most robust analytic strategy, especially when there are multiple mediating variables assessed at multiple data points. All of these considerations make meditational analyses a complex task.

Mediators of Treatment Outcome in Youth Anxiety Literature

\section{Parenting Variables as Treatment Mediators}

Although empirical research demonstrates that FCBT, which targets parenting variables (e.g., reinforcement skills training, parent relationships skills training) are successful in treating childhood anxiety disorders, it is unknown how these variables 
contribute towards positive treatment outcome. Theoretically, it is known that these variables are linked to childhood anxiety, but it is unknown how. In spite of the scant empirical support, research indicates that parenting variables may be hypothesized as mediators of positive child treatment outcome.

\section{Cognitive Variables as Treatment Mediators}

Self-talk, or youth, positive and negative self-statements, is one cognitive variable that has been examined in the youth anxiety literature as a predictor and mediator of treatment outcome. Kendall (1984) referred to this variable as "the power of nonnegative thinking." Negative self-statements, rather than positive self-statements, are viewed as being related to anxiety in youth (Treadwell \& Kendall, 1996; Kendall \& Treadwell, 2007). Several studies demonstrate empirical support of the relation between negative and positive self -statements and anxiety in youth (Ronan, Kendall, \& Rowe, 1994; Treadwell \& Kendall, 1996).

Another variable related to self-talk is the states-of-mind (SOM) ratio. The SOM model purports that a specific proportion of negative-to-positive self-statements accounts for positive coping and psychological adaptation and that dysfunction occurs when this ratio shifts (Schwartz \& Garamoni, 1986). The internal dialogue of conflict is characterized by a SOM ratio of 0.50 (ranges from .45 to .55 ) and is associated with worry, mild anxiety and depression. The negative dialogue is characterized by a ratio of 0.38 (ranges from 0.32 to 0.44 ) and is associated with moderate anxiety or depression. Negative monologue is characterized by SOM ratios greater than 0.68 and is characterized by excessive optimism and mania. 
Positive and negative self-talk and SOM ratios were targeted in Treadwell and Kendall (1996). Using participants' data involved in a randomized clinical trial (see Kendall, 1994), Treadwell and Kendall (1996) assessed 151 youths (ages 8 to 13 years, $M$ $=11.7$ years, $S D$ not reported) with primary anxiety diagnoses. The RCMAS, CDI, STAIC, and the Negative Affectivity Self-Statement Questionnaire for Children (NASSQ) (Ronan et al., 1994), were administered to youth. Parents completed the CBCL and teachers completed the TRF.

Significant findings indicated that youths' negative, but not positive self-talk, measured by the NASSQ, predicted the youths' anxiety severity self-ratings. Negative, but not positive self-talk, also predicted youth improvement in treatment outcome at posttreatment. When the treatment group was compared to the waitlist, treatment status significantly predicted the change in youths' negative and positive self-talk. Findings also indicated that the SOM ratio predicted changes in anxiety severity as measured by the youth rated RCMAS and A-Trait scale of the STAIC. Additional findings indicated that treatment status significantly predicted changes in the SOM ratio and that SOM ratio predicted improvement in youth anxiety after CBT.

In the same study, Treadwell and Kendall (1996) examined youths' self-talk and SOM ratio as a mediator of treatment outcome. Results indicated that self-talk served as a partial mediator of treatment outcome. ICBT produced changes in youths' positive and negative self-statements. However, only youths' anxious self-talk predicted changes in anxiety symptoms as measured by the RCMAS, STAIC-T/S.

These findings were replicated by Kendall and Treadwell (2007) using an independent sample of youth with anxiety disorders. Findings also indicated that SOM 
ratio mediated anxiety severity as measured by the RCMAS. However, the SOM ratio served as a mediator for only one outcome measure (youth ratings of self- anxiety on the RCMAS). ICBT was found to significantly produce changes in SOM ratio, which, in turn predicted changes self-reported anxiety levels.

\section{Peer Contextual Variables as Treatment Mediators}

Mediators and moderators of treatment response were examined in 88 children and adolescents (ages 8 to 12 years; $M=10.5$ years; $S D=1.5$ ) with a primary diagnosis of SOP (Alfano et al., 2009). The data for this study were drawn from two previously published randomized clinical trials (i.e., Beidel et al., 2000, $\mathrm{N}=31$; Beidel, Turner, Sallee, Ammerman, Crosby, \& Pachak., 2007; N = 57). Youth had been randomized to either SET-C ( $\mathrm{n}=57$, ages 7 to 17 years; $M=11.6$ years; $S D=2.6)$ (Beidel et al., 2007) or Testbusters (the control condition; $n=31$, ages 8 to 12 years; $M=10.5$ years; $S D=$ 1.6) (Beidel et al., 2000). The Alfano et al. (2009) examined whether child age and depressive symptoms moderated treatment outcome, such that older children and high levels of depressive symptoms would moderate SET-C posttreatment response. The authors also examined whether observers' ratings of youth social skills and children's ratings of loneliness mediated positive treatment response. Findings indicated that changes in social anxiety at posttreatment were mediated by youth ratings of loneliness. Neither age nor depressive symptoms moderated treatment outcome. Thus, the study demonstrated that peer variables (i.e., peer-youth relationship) mediated treatment response, though on only of the study's main outcome measure Youth social skills did not mediate treatment response on any of the study's main outcome measures. 
Parent and Youth Variables as Treatment Mediators: A Lagged Effect

Silverman et al. (2009) compared the relative efficacy of CBT with minimal parent involvement (CBT) and CBT with active parent involvement (CBT/P) in 119 youths ( 7 to 16 years; $M=9.93$ years; $S D=2.75$ ) with anxiety disorders. In $\mathrm{CBT} / \mathrm{P}$, in which the mother attended all treatment sessions with the child, three parenting variables were targeted: 1) parental positive-negative behaviors towards the child, 2) conflict in the parent-youth dyadic relationship, and 3) parental anxiety. The primary outcome measure completed by parents and youth was the RCMAS. Secondary outcome measures completed by parents were the CBCL and the Symptom Checklist-90-Revised (SCL-90R, Derogatis, 1983). Clinically significant improvement variables were clinician ratings, the CBCL-A/D, and the Children's Global Assessment Scale (C-Gas; Bird et al., 1993).

Findings indicated that youth anxiety was significantly reduced in both CBT and $\mathrm{CBT} / \mathrm{P}$ from pretreatment to posttreatment; and these effects were maintained at 12 month follow-up. The pattern of findings was similar for the study's primary and secondary outcome measures of youth anxiety symptoms, as well as clinically significant improvement variables. Another important finding in this study was that changes in youth rated reductions in parents' negative behavior from pretreatment to posttreatment predicted reductions in parents' negative behavior toward the child between posttreatment and the 12 month follow-up.

Silverman et al. (2009) also tested whether youth anxiety between pretreatment and posttreatment, as reported by parent and youth, served as a mediator between parent variables (i.e., parental positive-negative behaviors towards the child, conflict in the parent-youth dyadic relationship, and parental anxiety) measured at posttreatment and 
parent variables measured at 12 month follow-up. Findings indicated changes in youth anxiety from pretreatment to posttreatment were related to changes in parent anxiety during the same time period. This finding also indicated a lagged effect, such that improvement in youth anxiety between pretreatment and posttreatment takes time to result in changes in positive parenting behaviors, measured at the 12 month follow-up.

\section{Summary of Mediational Studies}

The above mentioned studies are the first to test mediators in youth anxiety treatment outcome research. There are limitations to these studies that are worth noting. In Albano et al. (2009) and Treadwell and Kendall (1996), the mediating variable was treated as an outcome variable and measured at the end of treatment. Treating the mediating variable as an outcome ignores the temporal relation between the change in the mediator and the change in the outcome (Weersing \& Weisz, 2002). In the Silverman et al. (2009) study one limitation was the correlational nature of some of the analyses and assumptions that were needed about the timing of causal dynamics between cause and effects. The current study will address these limitations by using more intensive and frequent measurement, including measuring of youth outcome and parent variables on a session by session basis (Kraemer et al., 2002). The above mentioned limitations are discussed further in the next section.

\section{Conceptual and Methodological Issues in Mediation Evaluation}

There are several conceptual and methodological issues that need to be considered when testing mediational models. Most meditational models use cross-sectional data that include three variables (1) a predictor variable (2) a mediator variable, and (3) an outcome variable. With this three variable meditational model, only one indirect effect 
can be examined, the effect of the predictor variable on the outcome variable, through its indirect effect on the mediator variable.

There are major drawbacks associated with using cross-sectional data to test meditation. One justification for using cross-sectional data to test mediation is the view that causes can have instantaneous effects (Simon, 1977). There are flaws with this reasoning. First, this assumption does not acknowledge that effects unfold over time. The magnitude of an effect should not be expected to be instant and constant over time. Thus, one drawback associated with using cross-sectional data to test mediation is it ignores the role of time and introduces biases in the estimation of mediation (Cole \& Maxwell, 2007). Another drawback of using cross-sectional data to test mediation is that the mediating variable measured at previous times is omitted. This omission results in "left out variable error," which has severe ramifications and is one of the most difficult types of misspecification errors to detect (Mauro, 1990). Left out variable error can lead to paths that are either over or under estimated in relation to their true value. This issue highlights the importance of examining the role of time lags in mediation.

In a review of 72 published studies that tested meditational hypotheses, Maxwell and Cole (2007) found that $53 \%$ of the studies used cross-sectional data in that they tested mediation with methods that did not allow time for an independent variable to have an effect on a dependent variable. Thirty-eight percent of the studies used longitudinal data to test mediational hypotheses. The authors referred to these longitudinal studies of mediation as half-longitudinal designs. These half-longitudinal designs had time that elapsed either between the measurement of the predictor variable and the mediating 
variable or between the mediating variable and the outcome variable, but never both. Thus, two of the three variables were measured at the same time.

Although progress has been made in meditational analyses in the child anxiety research literature, significant gaps remain regarding the appropriate time lags necessary for meditational analyses. Taken together, the review of meditational analyses in child therapy research, in general, and child anxiety, in particular, have not taken into account the importance of the time lag between when changes in the mediator translate into changes in the treatment outcome. Generally, assumptions are made regarding a minimal time lag necessary for mediation to occur.

Given that there are no theoretical or empirical explanations in the child therapy research regarding the appropriate time lags necessary for mediation, this dissertation sought to fill this gap in the literature. In doing so, this dissertation utilized an exploratory orientation using research designs that have frequent assessments of the mediators and the outcomes. This is the approach we used in the present study: We obtained brief measures of mediators and outcome at sessions 4, 6, 8, 10, 12 during the treatment sessions and then again at the immediate posttest.

Variables that have been found to effect treatment outcome (i.e., parent behavior, parent-youth relationship, child social skills, and peer-child relationship) served as mediators. Youth anxiety as reported by youth and mother served as the principal outcome.

\section{The Present Study}

The present study obtained brief measures of the mediators and outcome at sessions 4, 6, 8, 10, 12 and posttreatment to test two hypotheses. The first hypothesis 
was designed to determine empirically whether parent behavior, parent-youth relationship, child social skills, and peer-child relationship in CBTs were significant mediators of positive treatment response at sessions 4, 6, 8, 10, 12, and posttreatment. The second hypothesis was designed to determine empirically the time lags necessary for mediation to occur. 


\section{CHAPTER III}

\section{METHODOLOGY}

\section{Participants}

Participants were 168 youth (ages 6 to 16 years; 54\% males) and their mothers who presented to the Child Anxiety and Phobia Program (CAPP) at Florida International University (FIU). Pediatricians, school counselors, and other mental health professionals referred participants to the program. Seventy-four percent $(n=123)$ of the sample were Hispanic/Latino Americans, 20 percent $(n=33)$ were European Americans, and 6 percent $(n=10)$ were of other ethnic backgrounds. Inclusion criteria were a primary diagnosis with an anxiety disorder or phobic disorder, clinicians rating scale of severity score of 4 or greater, and age range of 7 to 16 years. Exclusionary criteria were developmental delays (e.g., autism), psychosis or schizophrenia, or current involvement in another psychosocial treatment.

Treatment completers and non-completers were compared at pretreatment using chi-square tests and t-tests along the following sociodemographic and clinical variables: socioeconomic status, parent's marital status, youth ethnicity, youth age, youth sex, interference rating on the youth's primary/target diagnosis, and youth's pretreatment anxiety levels. There were no statistically significant differences between completers and non-completers, with the exception of marital status $\left[\chi^{2}(1)=17.44, p<.001\right]$. More completer participants than non-completers were from families in which the mothers were in intact marriages.

This dissertation study provides data on sessions $4,6,8,10,12$, posttreatment mediation effects for 168 treatment completers (ages 6 to 16 years; $M=9.69$ years; $S D=$ 
2.25 ) and their parents. Table 1 provides sociodemographic information of the

participants who completed the treatment. As shown in Table 1, the youths' age range of 6 to 16 years reflects the modal age range of the age of onset of separation anxiety disorder (SAD), SOP, specific phobia (SP), and GAD in the population and is reflective of CAPP's referral patterns.

Measures

Parent and youth-rated brief measures of the mediator measures and the outcome measure were completed at sessions $4,6,8,10$, and 12 and full versions of the mediator measures and outcome measure at posttreatment. Brief measures of the mediators and outcome were administered to reduce subject burden given the intensive measurement that is needed every other session. All variables indicated below were assessed using both youth and parent versions of questionnaires.

\section{Primary Outcome Measure}

Children's Manifest Anxiety Scale - Revised (RCMAS) (child and parent versions) (Reynolds \& Richmond, 1978). The RCMAS served as the outcome measure. The RCMAS is a 37-item self-rating scale to which children respond either Yes or No to anxious symptoms. Using a three-week interval, Pela and Reynolds (1982) reported excellent test-retest reliability $(\mathrm{r}=.98)$. Significant correlations have been found between the Total Anxiety scale, trait anxiety, and fear ( $r \mathrm{~s}=.63$ to .88$)$ (Ollendick, 1983). The RCMAS has been used as the primary outcome measure in almost all past childhood anxiety trials and has been found to be a sensitive measure of change (e.g., Silverman et al., 1999a, b). The alpha coefficient in the present sample was .63. 
Revised Children's Manifest Anxiety Scale (Parent Version; RCMAS/P). The wording of RCMAS items was changed from, "I..." to "My child..." as done in past research (e.g., Kendall, 1994; Silverman et al., 1999). Twenty-eight items are rated either Yes or No and scored 1 or 0 . Summed items yield a Total Anxiety score. The alpha coefficient in the present sample was .69 .

Mediation Measures

Parenting Behavior Inventory (Child Report/Parent Report; Schluderman \& Schluderman, 1970) and Conflict Behavior Scale (Prinz, Foster, Kent, \& O'Leary, 1979) were used to assess the parenting skills and the parent-youth relationship variables. The Social Skills Rating System (SSRS; Gresham \& Elliott, 1990) and Friendship Questionnaire (FQ; Bierman \& McCauley, 1987) were used to assess the youths' socials skills and the peer-child relationship variables. These are described in more detail below. Parent Mediator Variables

Parenting Behavior Inventory. (Child Report/Parent Report; CRPBI \& PRPBI; Schludermann \& Schludermann, 1970). The CRPBI/PRPBI has 3 subscales, Psychological Control, Acceptance, and Firm/Lax Control, each of which contains ten questions. In this study, the Psychological Control subscale was used to assess the hypothesized parent mediator variable, Parent Autonomy Granting; the Acceptance subscale was used to assess Parent Acceptance of Child, the other hypothesized mediator. The CRPBI/PRPBI has been used in samples of children and adolescents referred to youth anxiety clinics and have been found to have satisfactory psychometrics (Siqueland et al., 1996). Test-retest reliability for the subscales range from .79 to .74 for the parent 
and child versions, respectively (Schluderman \& Schluderman, 1988). The alpha coefficients for the CRPBI and PRPBI in the current study were .83 and .75 , respectively. Conflict Behavior Questionnaire (Prinz et al., 1979). The Conflict Behavior Questionnaire (CBQ; Prinz et al., 1979) is a 44 items questionnaire that assesses the youth's: (1) positive and negative appraisal of the parent's behavior toward him/her (CBQ1) and (2) appraisal of conflict in the parent-youth dyadic relationship (CBQ2). Scores for the youth's positive and negative appraisal of the parent's behavior are derived from 28 items and range from 0 to 20 .

Youth completed the $\mathrm{CBQ}$ and parents completed the parent version of the CBQ. Scores for the youth's and parents appraisal of conflict are derived from 16 items and range from 0 to 10 . Reverse scoring is why the range is less than the total number of items. Robin and Foster (1989) reported a 6- to 8-week retest reliability of .57 and .84 for these scales. The CBQ subscale was analyzed in the present study as this was the variable (i.e., reducing conflict in the parent-youth relationship) that was targeted in the parent CBT (PCBT) condition. The alpha coefficients for the youth and parent versions of the CBQ in the current sample was .75.

Peer Mediator Variables

Friendship Questionnaire. The Friendship Questionnaire (FQ; Bierman \& McCauley, 1987) was used to evaluate youth's peer-youth relationships. The FQ contains 40 items that fall into 3 factors: Positive Interactions, Negative Interactions, and Extensiveness of Peer Network. Although the questionnaire includes eight open-ended questions about youth's friends, enemies, and peer interactions, relevant to the present study are the 32 items to which respondents rate the frequency of both positive (FQ-P) 
and negative interactions (FQ-N) with peers. The FQ discriminates between youth with positive versus rejected/neglected social status and correlates significantly with parent and teacher reports of behavior and social competence (Bierman \& McCauley, 1987). The alpha coefficients for the youth and parent versions of the FQ-P and the FQ-N in the current sample were .85 and .89 (youth rated) and .79 and .88 (parent rated), respectively. Social Skills Rating System. The Social Skills Rating System (SSRS; Gresham \& Elliott, 1990) provides a comprehensive assessment of the social skills behaviors of youth from several perspectives. The SSRS student/youth form (SSRS/C) consists of 34 questions: the parent form (SSRS/P) consists of 38 questions. Factor analysis of the SSRS/C and SSRS/P reveals 5 subscales: Empathy (SSRS-E), Cooperation (SSRS-C), Assertion (SSRS-A), Responsibility (SSRS-R), and Self-control (SSRS-S). Coefficient alpha reliabilities for the student form and parent form are .83 and .87 respectively. Gresham and Elliot (1990) provide extensive data to support the SSRS's validity including content, social, criterion, and construct. The total score of the SSRS was analyzed in the current study. The alpha coefficients for the youth and parent versions of the SSRS Total in the current sample were .86 and .89 , respectively. Procedure

Prior to conducting the study's procedures, parents were asked to sign an informed consent form and children signed an informed assent form. A diagnostician (a doctoral level graduate student) conducted assessment interviews and questionnaires in one session. All treatment measures were completed at pretreatment and posttreatment. Participants were randomly assigned to PCBT or GCBT in blocks of seven. All 
treatments were conducted by predoctoral level psychology graduate students who were supervised by a doctoral level psychologist.

\section{Treatment Conditions}

Participants were randomly assigned to PCBT or GCBT in blocks of seven (Flannery-Schroeder \& Kendall, 2000; Silverman et al., 1999b). The specific condition (PCBT or GCBT) used to start the random assignment process was determined by the toss of a coin. Assignment to treatment in blocks of seven was used to avoid delay in the formation of groups. Treatment manuals for PCBT and GCBT were developed to standardize the content of each treatment session. Nevertheless, therapists were advised to consider the developmental needs of the youth and proceed accordingly with the treatment protocol. Given the high proportion of Hispanic families in the sample $(75 \&)$, $8 \%$ of the treatments were delivered in a bilingual format (English and Spanish) by the request of the parent participating in PCBT. There were no statistically significant differences on any of the primary outcome variables as a result of treatment language in PCBT. All group treatments were delivered in English.

In PCBT, the youth and parents met with the therapist for a total of 60 minutes. In GCBT, the youth met in the group with the therapist for a total of 60 minutes. The parents of the youth who have been assigned to GCBT also had three brief group meetings (about 30 minutes) with each group therapist (at the start of the treatment program, the middle, and the end) to be kept abreast about the program and the youth's tasks and activities (similar to Barrett, 1998 and Flannery-Schroeder \& Kendall, 2000). Parents were not actively incorporated or involved in the youth's treatment in GCBT, thereby ensuring GCBT's distinctiveness from PCBT in terms of their targeting distinct 
contextual variables. The total number of sessions in both PCBT and GCBT was 12 to 14 sessions.

An outline of the basic core program as presented to participants is summarized below.

PCBT. Session 1. Introduction and discussion of presenting problems. Presentation of treatment rationale and goals, the importance of exposure and behavioral and cognitive strategies. Emphasis placed on working with anxious youth and their families, particularly parents. Present rationale for targeting parenting behaviors and parent-youth relationships. Explain out-of-session activities (Show That I Can; STIC jobs). Session 2. Review treatment rationale and goals. Explain "shaping" and help family construct anxiety hierarchy for the youth. Assign STIC task of generating list of rewards. Session 3. Explain importance of parental support and reinforcement. Present behavioral principles to families, such as contingency management and weekly parentyouth contracting, to be used to help youth face his/her anxieties. Finalize hierarchy and rewards that parents will provide to youth for successful exposure attempts. Discuss parent-youth relationships in regard to youth anxiety and elicit problem areas for families. Raise for discussion issues regarding parental control and acceptance of ones' youth. Devise first contract for families and assign first STIC task--approach in low anxiety situation. Session 4. Review STIC task. Conduct in-session exposure. Use family to provide feedback, modeling, and reinforcement. Continue discussions regarding parental control and acceptance. Ask family to select first problem area to be targeted in youth anxiety management. Begin training in problem solving. For STIC task: Arrange 2X@week when family will practice targeted problem area. Devise contract for 
exposure. Session 5. Review STIC task. Conduct in-session exposure. Begin training in communication skills. Ask family to select problem area to be targeted. Begin training using role-playing, behavioral rehearsal, feedback, etc. For STIC task: Arrange 2X @ week when family will practice new skill. Devise contract for exposure. Session 6. Review STIC task. Conduct in-session exposure. Continue practice in problem-solving and communication skills training, using role-playing, etc. Ask family to select problem area to be targeted. For STIC task: Arrange 2X @ week when family will practice targeted problem area. Also devise contract for exposure. Session 7. Review STIC task. Introduce cognitive component. Identify faulty cognitions, generate incompatible selfstatements, explore alternatives, etc. Explain fading of rewards (to begin next session). For STIC task: Arrange 2X @ week when family will practice a parent-youth relational area. Devise final contract. Practice cognitive strategies during exposure. Session 8. Review STIC task. Practice using communication and problem-solving skills. Introduce concept of self-evaluation and self-reward (now to replace parental rewards). Present 4step coping plan ("STOP"). For STIC task: Practice using STOP during exposure. Continue having family practice 2X @ week a targeted area. Session 9. Review STIC task. Conduct in-session exposure. Address difficulties in implementation of various strategies. For STIC task: Practice using STOP during exposure. Have family practice 2X @ week a targeted area. Session 10. Review STIC task. Conduct in-session exposure. Continue practice skills and STOP. STIC task: Practice STOP and practice 3X @ week a targeted area. Session 11. Review and present relapse prevention. For STIC task: Practice STOP. Session 12-14. Review progress, relapse prevention and termination. 
$G C B T$. Session 1. Introduction and discussion of presenting problems.

Presentation of treatment rationale and goals, the importance of exposure and behavioral and cognitive strategies. Emphasis placed on working with anxious youth and their peers in a group. Present rationale for targeting youth social skills behaviors and peer-youth relationships. Explain out-of-session activities (Show That I Can; STIC jobs). Session 2. Review treatment rationale and goals. Explain "shaping" and construct anxiety hierarchy. Have youth pair off and help each other devise a hierarchy so that each member of group has a hierarchy. Assign STIC task of generating list of rewards. Session 3. Explain importance of peer support and reinforcement. Present behavioral principles to youth, and explain how peers in-group will be using these principles, such as contingency management and weekly peer contracting, to help each other face their anxieties. Finalize hierarchy and rewards. Discuss peer-youth relationships in regard to youth anxiety and elicit problem areas for each youth in-group. Focus particularly on the notion of helping others, receiving help, etc. Devise first contract between group members (by having peers pair off) and assign first STIC task--approach in low anxiety situation. Session 4. Review STIC task. Conduct in-session exposure. Use peer group to provide feedback, modeling, and reinforcement. Ask each member of group to select first problem area to be targeted in youth social skills behaviors training. Train in social skills behaviors, including discussion of eye contact, ways to initiate and sustain conversations, etc. For STIC task: Arrange 2X@week when each group member will practice targeted problem area. Devise contract for exposure. Session 5. Review STIC task. Conduct in-session exposure. Continue training in youth social skills behaviors and peer relationship skills. Ask each group member to select problem area to be targeted. Begin training using role-playing, 
behavioral rehearsal, feedback, etc. For STIC task: Arrange 2X @ week when each group member will practice new skill. Devise contract for exposure. Session 6. Review STIC task. Conduct in-session exposure. Continue practice in youth social skills behaviors and peer relationship skills building, practice in giving and receiving compliments using roleplaying, etc. Ask each group member to select problem area to be targeted. For STIC task: Arrange 2X@week when each group member will practice targeted problem area. Also devise contract for exposure. Session 7. Review STIC task. Introduce cognitive component. Identify faulty cognitions, generate incompatible self-statements, explore alternatives, etc. Explain fading of rewards (to begin next session). For STIC task: Arrange 2X@ week when each group member will practice a youth-peer relational area. Devise final contract. Practice cognitive strategies during exposure. Session 8. Review STIC task. Continue practice using youth social skills behaviors and relationships skills. Introduce concept of self-evaluation and self-reward (now to replace peer rewards). Present 4-step coping plan ("STOP"). For STIC task: Practice using STOP during exposure. Continue having group practice 2X @ week a targeted area. Session 9. Review STIC task. Conduct in-session exposure. Address difficulties in implementation of various strategies. For STIC task: Practice using STOP during exposure. Have group members practice 2X @ week a targeted area. Session 10. Review STIC task. Conduct in-session exposure. Continue practice in skills and STOP. STIC task: Practice STOP and practice 3X@ week a targeted area. Session 11. Review and present relapse prevention. For STIC task: Practice STOP. Session 12-14. Review progress, relapse prevention, termination. 


\section{Therapists}

Because the two conditions require similar therapeutic skill levels, therapists were crossed between conditions as recommended by Kazdin (1994). Crossing therapists with condition allows for an analysis of the portion of patient change attributed to the therapists (therapist variance) that can be separated from the portion associated with treatment conditions (treatment variance) (Kazdin, 1994). All therapists received training in the proper administration of the interventions by Dr. Silverman. The training of therapists included the following: Therapists first familiarized themselves with the treatment protocols. Particular emphasis was placed on highlighting the overlap between the conditions (e.g., youth exposure) but also in ensuring that therapists understood the important distinctions between the two conditions. Dr. Silverman provided didactic and clinical training via role-playing of the interventions' procedures.

During the course of the dissertation study, Dr. Silverman conducted weekly supervision meetings with therapists to prepare for upcoming sessions and process sessions just completed. This included the review of the therapists' treatment notes, listening to a random selection of therapists' session tapes and providing ongoing feedback via instructions and role plays. Eight doctoral level graduate students sin psychology delivered the treatments to the majority of the youth in this dissertation study. There were no statistically significant differences between any of the therapists on any of the primary outcome variables.

\section{Study Design}

The study design utilized the recommendations of Cole and Maxwell (2003) for conducting tests of longitudinal mediation. Cole and Maxwell (2003) maintained that at 
least three waves of data are optimal for evaluating longitudinal mediation. In the regression of the outcome variable at a later time point on the predictor at a preceding time point, Cole and Maxwell (2003) recommend controlling for potential confounds, such as prior levels of the outcome variable, in the estimation of each pathway of the meditational model. This will allow for the control of this "almost ubiquitous 'third variable' confound"' (p. x; Cole \& Maxwell, 2003). To determine empirically the appropriate time lags necessary for mediation to occur, the model was evaluated using 6 time points (separated by approximately 2 months). This model used all 6 time points to examine the autoregressive, contemporaneous, and lagged effects of parent behavior, parent-youth relationship, child social skills, peer-child relationship on youth anxiety (See Figure 1). Including autoregressive, contemporaneous, and lagged effects in one model strengthens the conclusions about which mediated effects during which sessions are most essential and consistent in causing in effect on the outcome.

The data were analyzed using SEM in MPLUS Version 6. A full information framework was then employed where all paths were entered in one model and analyzed using SEM. To test autoregressive effects of the mediators and outcome variables, prior levels of the mediator/outcome variable at a later time were regressed unto the mediator/outcome variable at a preceding time point. To test for contemporaneous effects, the outcome variable at one time point was regressed onto the mediator variable during the same time point. To test lagged effects, paired time points in which time varying mediators were used for time-varying outcomes (i.e., social skills gained at session 6 to predict youth anxiety at session $8,10,12$, and posttreatment). 


\section{CHAPTER IV}

\section{RESULTS}

\section{Preliminary Analyses}

Outliers. Outlier analyses were undertaken prior to all major analyses. The analyses were both non-model based and model based. For the former, multivariate outliers were identified by examining leverage indices for each individual and defining an outlier as a leverage score four times greater than the mean leverage. There were no outliers found in the data using this approach. An additional set of outlier analyses were pursued using model based outlier analysis. This involved randomly selecting an indicator for each variable and then regressing the indicator for each endogenous variable onto an indicator for variables that the endogenous variable is assumed to be a linear function of. This analysis uses ordinary least squares (OLS) regression in a limited information estimation framework. Standardized dfbetas were examined for each individual and for each predictor, as well as the intercept. An outlier was defined as any case with an absolute standardized dfbeta larger than 1.0. There were no outliers found in the data using this approach.

Non-Normality. Univariate indices of skewness and kurtosis were examined to determine whether the absolute value of any of these indices was greater than 2.0. Nonnormality was evident in several of the variables. To account for the non-normality, structural equation modeling (SEM) analyses were pursued in MPLUS by using an estimator (MLR) robust to violations of normality based on the Huber-White algorithm.

Analysis of Missing Data. The first step in the analysis of missing data was to determine if there was systematic bias in the patterning of missing data. For a given 
measure, a dummy variable was constructed to indicate the presence or absence of missing data on that measure. Associations between these dummy variables and demographic as well as other study variables were examined. No significant associations were observed. Data revealed 30-40\% missing data on any give variable between sessions 4 and 12. Therefore full information maximum likelihood (FIML) missing data methodology was employed.

Indices of Fit. Following the recommendations of Bollen and Long (1993), a variety of global fit indices were used, including indices of absolute fit, indices of relative fit and indices of fit with a penalty function for lack of parsimony. These include the traditional overall chi square test of model fit, which should be statistically nonsignificant, the Root Mean Square Error of Approximation (RMSEA), which should be less than .08 to declare satisfactory fit), the $p$ value for the test of close fit, which should be statistically non-significant, and the Comparative Fit Index (CFI), which should be greater than .95 .

In addition to the global fit indices, more focused tests of fit were pursued. These included the standardized residual covariances, which should be between -2.00 and 2.00, and modification indices, which should be less than 4.00. The parameter estimates also were examined for Heywood cases. Heywood cases are parameter estimates with illogical values, such as negative error variances or intercorrelation values with absolute values greater than 1.0 (Kline, 2010). Care was taken to ensure there was no specification error. 
The correlations between the parents' ratings of youth anxiety and the youths' self ratings of anxiety were as follows: $.79, .77, .78, .64, .69, .46$ for sessions $4,6,8,10,12$, posttreatment, respectively. All correlations were statistically significant $(p<.05)$.

\section{Baseline to Posttreatment Effects.}

There were statistically significant changes from pretreatment to posttreatment on the primary outcomes measure, specifically, youth self ratings of anxiety using RCMAS $\left(t(150)=10.75, p<.05\right.$ eta $\left.^{2}=.44\right)$ and parents' ratings of their child's anxiety using the RCMAS/P $\left(t(155)=10.04, p<.05\right.$, eta $\left.^{2}=.39\right)$. The mean difference indicated decreased anxiety from pretreatment to posttreatment for both primary outcome measures (see Table 2). Contrasts that tested whether these effects differed by treatment condition yielded non-significant results, none of which remotely approached significance (all eta squares below .05).

In terms of the mediating variables, statistically significant changes in the youths' appraisals of the parents' positive and negative behaviors and conflict in the parent-youth dyadic relationship also occurred from pretreatment to posttreatment. For youths' ratings, appraisals of the parent became more positive $[\mathrm{CBQ} 1 ; t(162)=21.4, p<.05$, eta $\left.^{2}=.74\right]$ as did appraisals of the dyadic relationship [CBQ2; $t(163)=17.8, p<.05$, eta $^{2}$ $=.15]$ from pretreatment to posttreatment. For parents' ratings, appraisals of the parent became more positive $\left[\mathrm{CBQ} 1 ; t(36)=2.70, p<.05\right.$, eta $\left.^{2}=.05\right]$ as did appraisals of the parent-youth dyadic relationship $\left[\mathrm{CBQ} 2 ; t(36)=5.94, p<.05\right.$, eta $\left.^{2}=.19\right]$ (see Table 2). Contrasts revealed no significant differences as a function of treatment, with none of the effects remotely approaching significance (all eta squares below .05).

Statistically significant changes in psychological control and negative friendships 
occurred from pretreatment to posttreatment. For youth ratings, parents became less controlling [CRPBI, $t(155)=3.06, p<.05$ eta $\left.^{2}=.06\right]$ and negative friendships [FQ; $t$ $(154)=2.96, p<.05$ eta $\left.^{2}=.05\right]$ decreased from pretreatment to posttreatment. For parent reports, parents became less controlling [PRPBI; $t(155)=3.33, p<.05$, eta $^{2}=.07$ ] and negative friendships $\left[\mathrm{FQ} ; t(151)=3.06, p<.05\right.$, eta $\left.^{2}=.08\right]$ decreased from pretreatment to posttreatment (see Table 2). Significant changes in positive friendships and social skills were found only found for parent reports. For parent ratings youth increased in positive friendships $\left[\mathrm{FQ} ; t(155)=3.52, p<.05, \mathrm{eta}^{2}=.48\right]$ and social skills $\left[\mathrm{SSRS} ; t(151)=3.87, p<.05\right.$, eta $\left.^{2}=.09\right]$ from pretreatment to posttreatment (see Table 2). Contrasts revealed no difference as a function of treatment, with none of the effects remotely approaching significance (all eta squares below .05).

Given that this dissertation was not interested in examining mediation as a function of treatment condition, but rather to explore the time lags necessary for changes in the mediator to translate into changes in the outcome, the sample's data were pooled and treatment condition was entered into the models as a covariate.

\section{Structural Equation Modeling}

The data were further analyzed using SEM to yield insights into the underlying dynamics, which are depicted in Figure 1. Figure 1 represents the youth and parent models, respectively, which were tested. Mediators variables are introduced during treatment at Session 4, therefore session 4 data served as baseline for all analyses.

Five covariates were included in the analysis (1) mediating variables and the outcome variable as measured at session 4 (baseline), (2) youth sex, (3) youth age (4) comorbidity status, and (5) treatment condition. Paths were included from each of these 
variables to all endogenous variables. Figure 1 excludes the covariates as well as the correlations between exogenous variables to avoid clutter, but these were included in all model tests. Separate analyses were conducted for (1) youth self ratings of anxiety, parenting behavior, social skills, and friendships and (2) parent ratings of the youth anxiety, parenting behavior, youth social skills, and youth friendships.

The paths presented in Figure 1 represent contemporaneous, autoregressive, and lagged effects. Contemporaneous change estimates the extent to which changes in the mediating variables (youth appraisal of the parent, youth appraisal of the relationship, youth social skills, youth friendships) measured at sessions $4,6,8,10,12$,and posttreatment were associated with changes in the outcome variable (youth anxiety) during the same time. For example, an increase in youth ratings of their social skills at session 6 may be associated with a decrease in youth ratings of anxiety at session 6 .

Autoregressive effects estimates the extent to which changes in the outcome and mediating variables from sessions 4, 6, 8, 10, 12 and posttreatment were associated with changes in the same outcome and mediating variables from sessions 4, 6, 8, 10, 12 and posttreatment.

Lagged effects estimates the extent to which changes in the mediating variables from one session were associated with changes in youth anxiety symptoms at a later session. Such lagged effects make theoretical sense because it may take time for the changes in one variable to work their way through and produce changes in the other variable (Jaccard \& Jacoby, 2010).

The model in Figure 1 provided a good fit to the data for both the youth and parent models (see Table 3). Consistent with the prior analyses, there were no statistically 
significant path coefficients associated with the dummy variable representing the two treatment conditions. Hence no further mention is made of these.

I consider findings for contemporaneous, autoregressive, and lagged effects for youth and parent reports and only significant path coefficients are discussed below. Youth Ratings of Appraisal of Parental Positive-Negative Behaviors toward the Child

One significant contemporaneous effect was found for youth appraisal of parental positive-negative behaviors. Path $f$ was statistically significant (path $f=.18^{*}, p<.05$ ), suggesting that reductions in parents' negative behavior toward the youth at posttreatment were associated with reductions in youth ratings of anxiety during posttreatment (See Table 4).

Results also revealed that there were significant autoregressive effects in youth appraisal of parents' positive- negative behavior between sessions 4 and 6 (path a $=.58^{*}$, $p<.05$ ), sessions 6 and 8 (path $\mathrm{b}=.67^{*}, p<.05$ ), sessions 8 and 10 (path $\mathrm{c}=.64^{*}, p<$ .05 ), and sessions 10 and 12 (path $\mathrm{d}=.64^{*}, p<.05$ ). These findings suggest that reductions in parents' negative behavior toward the youth at sessions 4, 6, 8, and 10 were associated reductions in parents' negative behavior toward the youth in later sessions (See Table 6).

\section{Parent Ratings of Appraisal of Positive-Negative Behaviors toward Child}

In terms of parents' appraisal of their positive-negative behaviors, three significant contemporaneous effects were found. Path $a$ (path $\mathrm{f}=.32^{*}, p<.05$ ), path $c$ (path $\mathrm{c}=.48^{*}, p<.05$ ), and path $f$ (path $\mathrm{f}=.48^{*}, p<.05$ ) were statistically significant. These findings suggest that reductions in parents' negative behavior toward the youth at 
sessions 4,8 , and posttreatment were associated with reduced parent ratings of youth anxiety during sessions 4, 8, and posttreatment, respectively (See Table 5).

Results revealed that there were significant autoregressive effects in parents appraisal of their positive-negative behavior between sessions 4 and 6 (path a $=.42^{*}, p<$ $.05)$, sessions 6 and 8 (path $\left.\mathrm{b}=.51^{*}, p<.05\right)$, sessions 8 and $10\left(\right.$ path $\left.\mathrm{c}=.30^{*}, p<.05\right)$, sessions 12 and posttreatment (path $\mathrm{e}=1.83^{*}, p<.05$ ). These findings suggest that reductions in parents' negative behavior toward the youth, as reported by parent at sessions 4, 6, 8, and 12, were associated with reductions in parents' negative behavior toward the youth in later sessions (See Table 7).

There were statistically significant lagged effects in parent appraisal of their positive-negative behavior from session 4 to youth anxiety at session 12 (path $\mathrm{c}=-.68^{*}, p$ $<.05$ ) and posttreatment (path $\mathrm{d}=2.84^{*}, p<.05$ ). There was also a significant lagged effect from session 12 to posttreatment (path $\mathrm{j}=-3.18^{*}, p<.05$ ). These findings suggest that reductions in parents' negative behavior toward the youth at sessions 4 were associated with a decrease in parent ratings of youth anxiety symptoms at sessions 12 and a decrease in youth anxiety symptoms at posttreatment (See Table 9). Reductions in parents' negative behavior toward the youth at session 12 were associated with an increase in parent ratings of youth anxiety symptoms at posttreament. Youth Ratings of Appraisal of Conflict in the Parent-Youth Dyadic Relationship

Results revealed significant autoregressive effects in youth appraisal of conflict in the parent-youth dyadic relationship between sessions 4 and 6 (path $\mathrm{a}=.30^{*}, p<.05$ ), session 6 and 8 (path $\left.\mathrm{b}=.42^{*}, p<.05\right)$, sessions 8 and 10 (path $\left.\mathrm{c}=.55^{*}, p<.05\right)$. This 
suggests that reductions in negative relationships at sessions $4,6,8$, and 10 were associated with reductions in negative relationships at later sessions (See Table 6).

There were statistically significant lagged effects from youth appraisal of conflict in the parent-youth dyad relationship at sessions 6 (path $e=.97^{*}, p<.05$ ) and 8 (path $f=$ $-.73 *, p<.05)$ to youth anxiety at session 10 . This suggests that reductions in negative relationships at sessions 6 were associated with reductions in youth anxiety symptoms, as rated by youth, at session 10. This also suggests that reductions in negative relationships at session 8 were associated with an increase in youth ratings of youth anxiety symptoms at session 10 (See Table 8).

\section{Parent Ratings of Appraisal of Conflict in the Parent-Youth Dyadic Relationship}

Results revealed that there were significant autoregressive effects in parent appraisal of conflict in the parent-youth dyadic relationship between sessions 4 and 6 (path $\left.\mathrm{a}=.42^{*}, p<.05\right)$, sessions 6 and 8 (path $\mathrm{b}=.46^{*}, p<.05$ ), and sessions 12 and posttreatment (path $\mathrm{e}=2.40^{*}, p<.05$ ). This suggests that reductions in negative relationships, as rated by parents, at sessions 4,6 , and 12 were associated with reductions in negative relationships at later sessions (See Table 7).

There were statistically significant lagged effects in parents appraisal of conflict in the parent-youth dyadic relationship at sessions 6 (path $\left.\mathrm{f}=-4.11^{*}, p<.05\right), 10$ (path i $=4.59^{*}, p<.05$ ), and 12 (path $\mathrm{j}=-5.75^{*}, p<.05$ ) to youth anxiety at posttreatment. This suggests that reductions in negative relationships at session 6 were associated with an increase in parent ratings of youth anxiety at posttreatment. Reductions in negative relationships at session 10 were associated with a decrease in parent ratings of anxiety at 
posttreatment. Reductions in negative relationships at session 12 were associated with an increase in parent ratings of anxiety at posttreatment (See Table 9).

\section{Youth Ratings of Parental Acceptance}

In terms of parental acceptance as rated by youth, only one significant contemporaneous effect was found. Path $c$ was statistically significant (path $\mathrm{c}=.23^{*}, \mathrm{p}<$ $.05)$, suggesting that an increase in parental acceptance at session 8 was associated with an increase in youth ratings of youth anxiety during session 8 (See Table 4).

Results revealed significant autoregressive effects in parental acceptance as rated by youth between sessions 4 and 6 (path a $=.58^{*}, p<.05$ ), sessions 6 and 8 (path $\mathrm{b}=$ $\left..71^{*}, p<.05\right)$, sessions 8 and 10 (path $\left.\mathrm{c}=.50^{*}, p<.05\right)$, and sessions 12 and posttreatment (path $\mathrm{e}=4.60 *, p<.05$ ). This suggests that an increase in parental acceptance at sessions $4,6,8$, and 12 was associated with an increase in youth ratings of parental acceptance at later sessions (See Table 6).

There was one statistically significant lagged effect from parental acceptance as rated by youth, from session 6 (path $\mathrm{e}=-1.78^{*}, p<.05$ ) to youth anxiety at posttreatment. This finding suggests that an increase in parental acceptance at sessions 6 was associated with a decrease in youth ratings of youth anxiety symptoms at posttreatment (See Table 8).

Parent Ratings of Parental Acceptance

In terms of parental acceptance as reported by parent, only one significant contemporaneous effect was found. Path $b$ was statistically significant (path $\mathrm{b}=.28^{*}, p$ $<.05)$, suggesting that an increase in parental acceptance at session 6 was associated with 
an increase in parent ratings of youth anxiety, as rated by parents, during session 6 (See Table 5).

Results revealed that there were significant autoregressive effects in parental acceptance as reported by parent between sessions 4 and 6 (path $\mathrm{a}=.67^{*}, p<.05$ ), sessions 6 and 8 (path $\left.\mathrm{b}=.31^{*}, p<.05\right)$, sessions 8 and $10\left(\right.$ path $\left.\mathrm{c}=.39^{*}, p<.05\right)$, sessions 10 and 12 (path $\mathrm{d}=.46^{*}, p<.05$ ), and sessions 12 and posttreatment (path $\mathrm{e}=$ $1.87 *, p<.05)$. This suggests that an increase in parental acceptance at sessions $4,6,8$, 10, and 12 was associated with an increase in parental acceptance at later sessions (See Table 7).

There were statistically significant lagged effects in parental acceptance as rated by parent at sessions 4 to youth anxiety at session 10 (path $\mathrm{b}=-.43^{*}, p<.05$ ). These findings suggest that an increase in parental acceptance at session 4 was associated with a decrease in parent ratings of youth anxiety at session 10 (See Table 9).

\section{Youth Ratings of Parental Control}

In terms of parental control as reported by youth, two significant contemporaneous effects were found. Path $a$ (path $\left.\mathrm{a}=.18^{*}, p<.05\right)$ and path $b$ (path $\mathrm{b}=$ $.72 *, p<.05)$ were statistically significant, suggesting that a decrease in parental control at sessions 4 and 6 was associated with a decrease in youth ratings of youth anxiety during sessions 4 and 6, respectively (See Table 4).

Results also revealed significant autoregressive effects in parental control as reported by youth between sessions 4 and 6 (path $\mathrm{a}=.77^{*}, p<.05$ ), sessions 6 and 8 (path $\left.\mathrm{b}=.85^{*}, p<.05\right)$, sessions 8 and 10 (path $\left.\mathrm{c}=.57^{*}, p<.05\right)$, sessions 10 and 12 (path $\mathrm{d}=.41^{*}, p<.05$ ) and sessions 12 and posttreatment (path $\mathrm{e}=2.60 *, p<.05$ ). This 
suggests that a decrease in parental control at sessions $4,6,8,10$, and 12 was associated with a decrease in parental control at later sessions (See Table 6).

Based on youth reports, there were statistically significant lagged effects from parental control at sessions 6 to youth anxiety at session 8 (path a $=.22^{*}, p<.05$ ) and from to parental control at session 8 to youth anxiety at posttreatment (path $\mathrm{f}=2.13^{*}, p<$ $.05)$. These findings suggest that a decrease in parental control at sessions 6 and 8 was associated with a decrease in youth ratings of youth anxiety symptoms at sessions 8 and posttreatment, respectively (See Table 8).

\section{Parent Ratings of Parental Control}

In terms of parental control as reported by parent, one significant contemporaneous effect was found. Path $e$ was statistically significant (path $\mathrm{e}=.37^{*}, p<$ $.05)$, suggesting that a decrease in parental control at session 12 was associated with a decrease in parent ratings of youth anxiety at sessions 12 (See Table 5).

Results revealed that there were significant autoregressive effects in parental control as reported by parent between sessions 4 and 6 (path $a=.74^{*}, p<.05$ ), sessions 6 and 8 (path $\mathrm{b}=.81^{*}, p<.05$ ), and sessions 8 and 10 (path $\mathrm{c}=.38^{*}, p<.05$ ) and sessions 10 and 12 (path $\mathrm{d}=.40^{*}, \mathrm{p}<.05$ ). These findings suggest that a decrease in parental control at sessions $4,6,8$, and 10 was associated with a decrease in parental control at later sessions (See Table 7).

Based on parent reports, there were statistically significant lagged effects in parental control from sessions 4 (path $\mathrm{a}=.27^{*}, p<.05$ ) and 6 (path $\mathrm{e}=-.27^{*}, p<.05$ ) to youth anxiety at sessions 8 . There was also a significant lagged effects in parental control from session 8 (path $\mathrm{h}=1.61^{*}, \mathrm{p}<.05$ ) to youth anxiety at posttreatment. This 
suggests that a decrease in parental control at sessions 4 was associated with a decrease in parent ratings of youth anxiety at session 8 . This also suggests that a decrease in parental control at session 6 was associated with increase in parent ratings of youth anxiety at session 8. A decrease in parental control at session 8 was associated with an increase in parent ratings of youth anxiety at posttreatment (See Table 9).

\section{Youth Self-Ratings of Positive Friendships}

In terms of positive friendships as reported by youth, one significant contemporaneous effect was found. Path $f$ was statistically significant (path $\mathrm{f}=-.10^{*}, \mathrm{p}<$ $.05)$, suggesting that an increase in positive friendships at posttreatment was associated with a decrease in youth ratings of youth anxiety at posttreatment (See Table 4).

Results revealed that there were significant autoregressive effects in positive friendships as reported by youth between sessions 4 and 6 (path $\mathrm{a}=.74^{*}, p<.05$ ), sessions 6 and 8 (path $\left.\mathrm{b}=.63^{*}, p<.05\right)$, sessions 8 and 10 (path $\left.\mathrm{c}=.20^{*}, p<.05\right)$, and sessions 10 and 12 (path $d=.56^{*}, p<.05$ ). This suggests that an increase in positive friendships at sessions $4,6,8$, and 10 was associated with an increase in positive friendships at later sessions (See Table 6).

\section{Parent Ratings of Youth Positive Friendships}

In terms of positive friendships as reported by parent, only one significant contemporaneous effect was found. Path $d$ was statistically significant (path $\mathrm{d}=.17^{*}, \mathrm{p}$ $<.05$ ), suggesting that an increase in positive friendships at session 10 was associated with an increase in parent ratings of youth anxiety at session 10 (See Table 5).

Results revealed that there were significant autoregressive effects in positive friendships, as reported by parents, between sessions 4 and $6\left(0.53^{*}, p<.05\right)$, sessions 6 
and $8\left(\right.$ path $\left.\mathrm{b}=.55^{*}, p<.05\right)$, and sessions 8 and 10 (path $\left.\mathrm{c}=.45^{*}, p<.05\right)$. This suggests that an increase in positive friendships at sessions 4,6 , and 8 was associated with an increase in positive friendships at later sessions (See Table 7).

There was one statistically significant lagged effect in positive friendships as reported by parent at session 6 to youth anxiety at session 8 (path $\mathrm{e}=.21^{*}, p<.05$ ). This finding suggests that an increase in positive friendships at sessions 6 was associated with an increase in parent ratings of youth anxiety at session 8 (See Table 9).

\section{Youth Self-Ratings of Negative Friendships}

In terms of negative friendships as reported by youth, two significant contemporaneous effects were found. Path $a$ (path $\left.\mathrm{a}=.15^{*}, p<.05\right)$ and path $f($ path $\mathrm{f}=$ $\left..13^{*}, p<.05\right)$ were statistically significant, suggesting that a decrease in negative friendships at sessions 4 and posttreatment were associated with a decrease in youth ratings of youth anxiety at sessions 4 and posttreatment, respectively (See Table 4).

Results revealed that there were significant autoregressive effects in negative friendships between sessions 4 and 6 (path $\mathrm{a}=.34^{*}, p<.05$ ), and sessions 10 and 12 (path $\mathrm{d}=.30^{*}, p<.05$ ). This suggests that a decrease in negative friendships at sessions 4 and 10 were associated with a decrease in negative friendships at later sessions (See Table 6).

There was one statistically significant lagged effect from negative friendships at sessions 6 to youth anxiety at session 12 (path $\left.\mathrm{c}=-.10^{*}, p<.05\right)$. This finding suggests that a decrease in negative friendships at sessions 6 were associated with increase in youth ratings of youth anxiety symptoms at sessions 12 (See Table 8). 


\section{Parent Ratings of Youth Negative Friendships}

In terms of negative friendships as reported by parent, two significant contemporaneous effects were found. Path $b$ (path $\mathrm{b}=.40^{*}, p<.05$ ) and path $d$ (path $\mathrm{d}=$ $\left..38^{*}, p<.05\right)$ were statistically significant, suggesting that a decrease in negative friendships at session 6 and session 10 was associated with a decrease in parent ratings of youth anxiety during sessions 6 and 10, respectively (See Table 5).

Results revealed that there were significant autoregressive effects in negative friendships between sessions 4 and 6 (path $\left.\mathrm{a}=.49^{*}, p<.05\right)$ ), sessions 8 and 10 (path $\mathrm{c}=$ $.43^{*}, p<.05$ ), and sessions 10 and 12 (path $\mathrm{d}=.44^{*}, p<.05$ ) (See Figure 2). This suggests that a decrease in negative friendships at sessions 4,8 , and 10 were associated with a decrease in negative friendships in the session succeeding (See Table 7).

There was one statistically significant lagged effect in negative friendships at session 6 to youth anxiety at posttreatment (path $\mathrm{f}=-3.85^{*}, p<.05$ ). This finding suggests that a decrease in negative friendships at sessions 6 were associated with an increase in parent ratings of youth anxiety at posttreatment (See Table 9).

\section{Youth Self-Ratings of Social Skills}

In terms of social skills as reported by youth, one significant contemporaneous effect was found. Path $f$ was statistically significant (path $f=-.13^{*}, p<.05$ ), suggesting that an increase in social skills at posttreatment was associated with a decrease in youth ratings of youth anxiety symptoms at posttreatment (See Table 4).

Based on youth reports, results revealed that there were significant autoregressive effects in social skills between sessions 4 and 6 (path a $=.68^{*}, p<.05$ ), sessions 6 and 8 (path $\mathrm{b}=.55^{*}, p<.05$ ), sessions 10 and 12 (path $\mathrm{d}=.66^{*}, p<.05$ ), and sessions 12 and 
posttreatment (path e $=2.42^{*}, p<.05$ ) (See Table 6). This suggests that an increase in social skills at sessions 4, 6, 10 and 12 was associated with an increase in social skills in the session succeeding (See Table 6).

\section{Parent Ratings of Youth Social Skills}

In terms of social skills as reported by parent, two significant contemporaneous effects were found. Path $d$ (path $\left.\mathrm{d}=.16^{*}, p<.05\right)$ and path $f\left(\right.$ path $\left.\mathrm{f}=-.09^{*}, p<.05\right)$ were statistically significant, suggesting that an increase in social skills at session 10 and posttreatment were associated with an increase in youth anxiety at session 10 and a decrease in parent ratings of youth anxiety at posttreatment, respectively (See Table 5).

Results revealed that there were significant autoregressive effects in social skills between sessions 4 and 6 (path a $=.59^{*}, p<.05$ ), sessions 8 and 10 (path $\mathrm{c}=.88^{*}, p<$ .05 ), and sessions 12 and posttreatment (path e $=1.66^{*}, p<.05$ ) (See Figure 2). This suggests that an increase in social skills at sessions 4, 8, and 12 were associated an increase in social skills at later sessions (See Table 7).

There were two statistically significant lagged effect in social skills from session 8 to youth anxiety at session 10 (path $\mathrm{g}=-.25^{*}, p<.05$ ). There was also a statistically significant lagged effect in social skills from session 12 to parent ratings of youth anxiety at posttreatment (path $\mathrm{j}=-1.34^{*}, p<.05$ ). This suggests that an increase in social skills at sessions 8 was associated with a decrease in parent ratings of youth anxiety at session 10. This also suggests that an increase in social skills at session 12 is associated with a decrease in parent ratings of youth anxiety at posttreatment (See Table 9). 


\section{CHAPTER V \\ DISCUSSION}

The current study examined whether variables that have been found to affect treatment outcome (i.e., parent behaviors, parent-youth relationship, child social skills, peer-child relationship) serve as potential mediators over multiple time points of child and adolescent outcomes following a CBT anxiety program. Assessments of these variables were made by using parent and youth ratings. The methodology employed helped elucidate how parent and youth variables mediate treatment outcome in youth anxiety disorders. The methodology also advanced current understanding of how positive outcome may be produced in youth anxiety CBTs. The current study examined the mediating variables measured at multiple time points throughout treatment (i.e., sessions $4,8,6,10,12$, and post-treatment) to determine the time lags necessary for changes in the mediator variable to translate into changes in the outcome on treatment gains. This aspect of my dissertation examined an important area in meditational analysis that is limited in the child and adolescent treatment research, in general, and in treatment research on anxiety disorders in youth.

Summary of Dissertation Findings

Overall, results indicate a pattern of anxiety reduction for both youth and parent ratings of youth anxiety from baseline (session 4) to posttreatment. This is not surprising given that CBT administered in family and group formats have both been found to be efficacious in reducing anxiety in youth with anxiety disorders (e.g., Barrett et al., 1996; Bögels \& Siqueland, 2006; Silverman et al., 2009) and peers (e.g., Beidel et al., 2000; Flannery-Schroeder \& Kendall, 2000; Silverman et al., 1999b). 
In terms of the mediating variables, results indicate that all parent-rated mediator variables demonstrated significant positive change from baseline to posttreatment (i.e., Appraisal of Parent, Appraisal of Dyad). CRPBI and Conflict Behavior Scale demonstrated significant positive change from baseline to post-treatment. Positive friendships and social skills did not demonstrate significant positive change from baseline to post-treatment.

Results overall demonstrated that mediation was evident for all variables rated by parents (i.e., appraisal of parent, appraisal of dyad, parental acceptance and control, positive and negative friendships, social skills). In terms of youth ratings, mediation was only found for the appraisal of dyad, parental acceptance and control, and negative friendships. Although a change in the mediators were expected to increase the probability of a change in youth and parent ratings of youth anxiety, there were several instances in which the mediator did not result in improvement (e.g., reductions in negative relationships at session 6 were associated with an increase in youth anxiety posttreatment). Later on in treatment, the same mediator variable resulted in a decrease in youth anxiety (e.g. negative relationships at session 10 were associated with a decrease in youth anxiety at posttreatment). This pattern was evident for both parent and youth rated mediators. The above mentioned findings warrant some discussion.

In psychotherapy research a common assumption is that therapeutic change is gradual and linear (Hayes, Laurenceau, Feldman, Strauss, \& Cardaciotto, 2007). The research designs and statistics used to study mediation often reflect this assumption. The mediators are measured once or twice and then compared between groups or correlated with symptom change at the end of treatment. There is accumulating evidence indicating 
that therapeutic change may not always be linear, but discontinuous and nonlinear (Hayes et al., 2007; Tang \& DeRubeis, 1999). This nonlinearity is also likely in exposure- based therapies (Hayes et al., 2007).

Exposure-based therapies for anxiety disorders are characterized by gradual exposure to the feared object or situation. This application is based on the assumption that the emotional fear arousal associated with anxiety must ultimately be increased prior to the introduction of cognitive restructuring (Foa, Huppert, \& Cahill, 2006; Foa \& Kozak, 1986). This process of change can be characterized by a period of fluctuation, with transient periods of symptom exacerbation (Hayes et al., 2007).

Consistent with this line of reasoning, Heimberg and Becker (2002) described three patterns of symptom fluctuation in anxiety ratings during in-session exposures in social anxiety. One pattern is referred to as "steady decline" and is described as gradual and linear. The other two patterns are referred to as the "spike" and "habituation curve" and are characterized by a brief period of symptom exacerbation that is discontinuous and curvilinear. Similarly, Nishith, Resick, and Griffin (2002) found that a curvilinear function best fit the total PTSD symptom reduction in a sample of women receiving therapy for PTSD, suggesting that anxiety increases before it decreases. This dissertation study demonstrated that the mediators at multiple time points influenced youth anxiety in a fluctuating manner, such that a decrease in skills at one given session may cause a decrease or increase of youth anxiety at a later session. This dynamic between the mediator and outcome may be reflective of the process of therapeutic change and should be considered as a plausible theoretical perspective that explains change in therapy. 
Findings from meditational analyses are consistent with a model that suggests lagged effects. Skills gained from session to session took time to exert their effect on youth anxiety. Lagged effects were evident for all parent-rated mediators and were only evident for youth rated CBQ II, parental acceptance and control, and negative friendships.

\section{Contribution of the Present Study and Implications}

The theoretical, empirical, and clinical contributions of the present study are summarized below including potential implications.

Theoretical. Consistent with past studies, the study's findings provide additional support for the use of cognitive and behavioral treatment procedures to reduce anxiety and its disorders in youth. Baseline to posttreatment effects make it clear that gradual exposure to feared objects or situation coupled with cognitive restructuring reduces youth anxiety (Silverman et al., 2008).

The evaluation of mediators of treatment outcome in youth anxiety disorders advances current understanding of the mechanisms underlying therapeutic change (Kazdin \& Nock 2003; Weersing \& Weisz, 2002). Findings suggest that the hypothesized mediators (i.e., parent behaviors, parent-youth relationship, child social skills, peer-child relationship) mediate youth anxiety treatment response. These findings not only informed theory construction in youth anxiety treatment, but more importantly, provided data that both researchers and clinicians can use to appropriately select variables that lead to significant symptom reduction.

Empirical. The present study also provided an empirical contribution to child anxiety research literature in its design and measurement strategies. It is important to note 
that this is the first study in the child anxiety research literature to empirically test for mediators of treatment outcome measured at multiple time points. The frequent assessment of the mediators and outcome allowed to identify processes of change which would have not been possible with the traditional measurement time points which include a pre, mid, and post assessment. This measurement strategy provided useful information regarding the role of time in therapeutic change.

The current findings also provided support for considering the role of time when examining mediators of therapeutic change in cognitive and behavioral treatment for reducing anxiety and related disorders in youth. The lagged effects challenge assumptions that are made regarding a minimal/instantaneous time lag necessary for mediation to occur. These findings underscore the importance of accounting for the role of time when conducting meditational analyses in child and adolescent treatment research. The use of traditional methods which includes a pre, mid, and post design to test for mediation may have resulted in erroneous conclusions regarding mediation in this study.

Clinical. The current findings provide evidence-based information that clinicians might use when their intervention targets include variables such as parental psychological control and acceptance, parent-youth relationship skills, social skills. Mediational findings indicate that targeting such variables yield significant reduction of anxiety symptoms in youth.

Examining the time lags between when changes in the mediator translate into changes in the outcome on treatment gains was of particular importance because it provides insight regarding the effects of crucial components on the outcome on treatment 
gains occur. This allowed for some perceptive on how long a skill (e.g. parenting skills, child social skills) needs to be maintained to result in positive treatment response.

\section{Limitations and Future Research Directions}

The current dissertation made an important contribution by examining mediators of treatment outcome at multiple time points. However, it is important to note some limitations of the study. First, the findings must be considered preliminary because this study only included one measure for each construct. Future research should consider using several measures to better operationalize the constructs of interest. Also, using the same measures at more than one point in time is a statistical limitation which created a shared method variance. The inclusion of additional measures of the mediators and outcome variable and modeling the shared variance by allowing correlations between appropriate pairs of disturbance terms could account for the shared method variance.

Second, the generalizability of our findings may be limited given that $74 \%$ of participants in this sample were Hispanic. As a result, findings may not generalize to youth of other ethnic background. Future research should consider using a diverse sample large enough in order to draw conclusions about the mediated relations for different ethnic groups. This would provide important information for interventions that identify what works, and for whom (Kramer et al., 2002).

Third, brief versions of the measures were used in an effort to reduce participant burden. Although the brief versions of these measures showed acceptable reliability estimates, future research should consider using established versions of measures that have been shown to be reliable and valid with youth. 
Last, the current study did not test for suppression effects. The pattern of coefficients observed in the findings may be an indication of the presence of inconsistent mediation (Davis, 1985) or suppression effects (Cliff \& Earleywine, 1994; Tzelgov \& Henik, 1991). A suppression effect would be present when the direct and mediated effects of an independent variable on a dependent variable have opposite signs (Cliff \& Earleywine, 1994; Tzelgov \& Henik, 1991). Given that this study did not test for suppression effects, results should be interpreted with caution.

The current study adds to the limited body of literature (Alfano et al., 2009 \& Silverman et al., 2009) on parent and peer variables as mediators of youth anxiety treatment. The results of this study provided preliminary steps for future investigations of mediation in the child anxiety research area, particularly regarding the timing of mediated effects. 
Table 1

Demographic and Diagnostic Information

\begin{tabular}{|c|c|c|c|c|}
\hline \multirow[b]{2}{*}{ Variable } & \multicolumn{4}{|c|}{$(n=168)$} \\
\hline & $n$ & $\%$ & $M$ & $S D$ \\
\hline Age (years) & & & 9.71 & 2.28 \\
\hline Gender (male) & 88 & 52 & & \\
\hline \multicolumn{5}{|l|}{ Target diagnosis } \\
\hline Separation anxiety & 68 & 40.5 & & \\
\hline Social phobia & 35 & 20.8 & & \\
\hline Specific phobia & 28 & 16.7 & & \\
\hline Generalized anxiety & 24 & 14.3 & & \\
\hline OCD & 7 & 4.2 & & \\
\hline PD w/ Agoraphobia & 0 & 0.0 & & \\
\hline PD w/out Agoraphobia & 0 & 0.0 & & \\
\hline Selective Mutism & 1 & 0.6 & & \\
\hline \multicolumn{5}{|l|}{ Ethnic background } \\
\hline Euro-American & 33 & 19.6 & & \\
\hline Hispanic/Latino & 123 & 73.2 & & \\
\hline African-American & 5 & 3.0 & & \\
\hline Other/not reported & 7 & 4.2 & & \\
\hline \multicolumn{5}{|l|}{ Annual income } \\
\hline$\$ 0-\$ 20,999$ & 20 & 11.9 & & \\
\hline$\$ 21,000-\$ 40,999$ & 35 & 20.8 & & \\
\hline$\$ 41,000-\$ 60,999$ & 25 & 14.9 & & \\
\hline$\$ 61,000-\$ 80,999$ & 21 & 12.5 & & \\
\hline$\$ 81,000-\$ 99,999$ & 18 & 10.7 & & \\
\hline$\$ 100,000-\$ 149,999$ & 21 & 12.5 & & \\
\hline$>\$ 150,000$ & 15 & 8.9 & & \\
\hline Not reported & 13 & 7.7 & & \\
\hline \multicolumn{5}{|l|}{ Marital Status } \\
\hline Married & 135 & 80.4 & & \\
\hline Divorced & 16 & 9.5 & & \\
\hline Single & 1 & 0.6 & & \\
\hline Separated & 8 & 4.8 & & \\
\hline Remarried & 0 & 0.0 & & \\
\hline \multicolumn{5}{|l|}{ Unmarried living } \\
\hline $\mathrm{w} /$ partner & 3 & 1.8 & & \\
\hline Widowed & 0 & 0.0 & & \\
\hline Not reported & 5 & 3.0 & & \\
\hline
\end{tabular}

Note. $\mathrm{OCD}=$ Obsessive Compulsive Disorder. $\mathrm{PD}=$ Panic Disorder. $\mathrm{w} /=$ with. 
Table 1 (Continued)

Demographic and Diagnostic Information in the Two Treatment Conditions for Treatment Completers

\begin{tabular}{|c|c|c|c|c|}
\hline \multirow[b]{2}{*}{ Variable } & \multicolumn{4}{|c|}{$\operatorname{PCBT}(n=168)$} \\
\hline & $n$ & $\%$ & $M$ & $S D$ \\
\hline \multicolumn{5}{|l|}{ Mother's Education } \\
\hline Grade school & & 0.0 & & \\
\hline Some high school & 5 & 3.1 & & \\
\hline High school & 14 & 8.6 & & \\
\hline GED & 3 & 1.9 & & \\
\hline Some college & 29 & 17.3 & & \\
\hline College & 30 & 17.9 & & \\
\hline Bachelor's & 38 & 22.6 & & \\
\hline Master's & 21 & 12.5 & & \\
\hline Ph.D. & 5 & 3.0 & & \\
\hline Technical Degree & 11 & 6.5 & & \\
\hline Advanced Degree & 4 & 2.4 & & \\
\hline Other/Not Reported & 8 & 4.8 & & \\
\hline \multicolumn{5}{|l|}{ Father's Education } \\
\hline Some grade school & 2 & 1.2 & & \\
\hline Grade school & 3 & 1.8 & & \\
\hline Some high school & 9 & 5.4 & & \\
\hline High school & 11 & 6.5 & & \\
\hline GED & 4 & 2.4 & & \\
\hline Some college & 21 & 12.5 & & \\
\hline College & 32 & 19.0 & & \\
\hline Bachelor's & 35 & 20.8 & & \\
\hline Master's & 19 & 11.3 & & \\
\hline Ph.D. & 8 & 4.8 & & \\
\hline Technical Degree & 10 & 6.0 & & \\
\hline Advanced Degree & 5 & 3.0 & & \\
\hline Other/Not Reported & 9 & 5.4 & & \\
\hline
\end{tabular}

Note . Mother's Education $=$ Highest education mother attained. Father's Education $=$ Highest education father attained. $\mathrm{PCBT}=$ Parent-involvement cognitive behavior treatment. 
Table 2

Means (Standard Deviations) for Child Symptom Variables and Mediating Variables at Pretreatment and Posttreatment

\begin{tabular}{lcccc}
\hline & Pretreatment & Posttreatment \\
\hline RCMAS & $12.27(7.19)$ & $7.49^{\mathrm{a}}$ & $(6.39)$ \\
RCMAS/P & $12.62 \quad(5.58)$ & $8.24^{\mathrm{a}}$ & $(5.78)$ \\
CBQ Appraisal of Mother & $10.11 \quad(3.68)$ & $4.68^{\mathrm{a}}$ & $(4.71)$ \\
CBQ Appraisal of Mother/P & 5.05 & $(4.57)$ & $4.10^{\mathrm{a}}$ & $(4.10)$ \\
CBQ Appraisal of Dyad Conflict & $61.91(13.11)$ & $3.13^{\mathrm{a}}$ & $(2.76)$ \\
CBQ Appraisal of Dyad Conflict/P & 6.84 & $(1.84)$ & $1.70^{\mathrm{a}}$ & $(2.24)$ \\
CRPBI (Maternal Acceptance) & 26.58 & $(3.93)$ & $26.21^{\mathrm{a}}$ & $(4.44)$ \\
PRPBI (Maternal Acceptance) & 17.39 & $(2.60)$ & $17.53^{\mathrm{a}}$ & $(2.53)$ \\
CRPBI (Psychological Control) & 17.80 & $(4.44)$ & $16.79^{\mathrm{a}}$ & $(4.58)$ \\
PRPBI (Psychological Control) & 5.06 & $(3.52)$ & $4.20^{\mathrm{a}}$ & $(3.40)$ \\
Friendship Questionnaire (Positive) & $48.72(13.87)$ & 50.87 & $(13.34)$ \\
Friendship Questionnaire (Positive)/P & $43.46(12.44)$ & $46.37^{\mathrm{a}}$ & $(12.14)$ \\
Friendship Questionnaire (Negative) & $32.50(11.80)$ & $29.87^{\mathrm{a}}$ & $(13.25)$ \\
Friendship Questionnaire (Negative)/P & $28.05 \quad(9.42)$ & $25.18^{\mathrm{a}}$ & $(6.88)$ \\
SSRS & $55.97(10.78)$ & 58.17 & $(12.24)$ \\
SSRS/P & $48.51(10.92)$ & $51.01^{\mathrm{a}}$ & $(10.69)$ \\
\hline & & & & \\
\hline
\end{tabular}

Note. Posttreatment means with superscript reflect statistically significantly changes from pre-treatment to posttreatment $(p<.05)$. RCMAS $=$ Revised Children's Manifest Anxiety Scale (Reynolds \& Richmond, 1978), P = parent, CBQ = Conflict Behavior Questionnaire (Prinz et al., 1979) (Youth version), CRPBI/PRPBI = Parenting Behavior Inventory-Psychological Control (Child Report/Parent Report; CRPBI \& PRPBI; Schluderman \& Schluderman, 1970), (Friendship Questionnaire (FQ; Bierman \& McCauley, 1987), SSRS= Social Skills Rating System (SSRS; Gresham \& Elliott, 1990). 
Table 3

Fit Indices for Major Analyses Using Structural Equation Modeling

\begin{tabular}{|c|c|c|c|c|}
\hline & Chi Square & CFI & RMSEA & p Close \\
\hline CBQ Appraisal of Parent and RCMAS & 0.17 & 0.98 & 0.03 & 0.78 \\
\hline CBQ Appraisal of Parent and RCMAS/P & 0.09 & 0.97 & 0.04 & 0.61 \\
\hline $\begin{array}{l}\text { CBQ Appraisal of Dyad Conflict and } \\
\text { RCMAS }\end{array}$ & 0.05 & 0.96 & 0.05 & 0.55 \\
\hline $\begin{array}{l}\text { CBQ Appraisal of Dyad Conflict and } \\
\text { RCMAS/P }\end{array}$ & 0.02 & 0.97 & 0.06 & 0.37 \\
\hline $\begin{array}{l}\text { CRPBI (Maternal Acceptance) and } \\
\text { RCMAS }\end{array}$ & 0.13 & 0.98 & 0.04 & 0.74 \\
\hline $\begin{array}{l}\text { PRPBI (Maternal Acceptance) and } \\
\text { RCMAS/P }\end{array}$ & 0.66 & 1.00 & $<0.000$ & 0.98 \\
\hline $\begin{array}{l}\text { CRPBI (Psychological Control) and } \\
\text { RCMAS }\end{array}$ & 0.00 & 0.95 & 0.07 & 0.08 \\
\hline $\begin{array}{l}\text { PRPBI (Psychological Control) and } \\
\text { RCMAS/P }\end{array}$ & 0.04 & 0.98 & 0.05 & 0.47 \\
\hline $\begin{array}{l}\text { Friendship Questionnaire (Positive) and } \\
\text { RCMAS }\end{array}$ & 0.26 & 0.99 & 0.03 & 0.83 \\
\hline $\begin{array}{l}\text { Friendship Questionnaire (Positive) and } \\
\text { RCMAS/P }\end{array}$ & 0.04 & 0.96 & 0.05 & 0.47 \\
\hline $\begin{array}{l}\text { Friendship Questionnaire (Negative) and } \\
\text { RCMAS }\end{array}$ & 0.00 & 0.94 & 0.06 & 0.19 \\
\hline $\begin{array}{l}\text { Friendship Questionnaire (Negative) and } \\
\text { RCMAS/P }\end{array}$ & 0.00 & 0.92 & 0.07 & 0.05 \\
\hline SSRS and RCMAS & 0.06 & 0.97 & 0.05 & 0.60 \\
\hline SSRS and RCMAS/P & 0.37 & 0.02 & 1.00 & 0.91 \\
\hline
\end{tabular}

Note. Chi square is goodness of fit index based on maximum likelihood criterion (model degrees of freedom = 2), CFI is the Comparative Fit Index, RMSEA is the Root Mean Square Error Approximation test and $\mathrm{p}$ Close is the $\mathrm{p}$ value for close fit associated with the RMSEA. RCMAS = Revised Children's Manifest Anxiety Scale (Reynolds \& Richmond, 1978), P = parent, CBQ = Conflict Behavior Questionnaire (Prinz et al., 1979) (Youth version), $\mathrm{CRPBI} / \mathrm{PRPBI}=$ Parenting Behavior Inventory-Psychological Control (Child Report/Parent 
Report; CRPBI \& PRPBI; Schluderman \& Schluderman, 1970), (Friendship Questionnaire (FQ; Bierman \& McCauley, 1987), SSRS= Social Skills Rating System (SSRS; Gresham \& Elliott, 1990). 
Table 4

Selected Contemporaneous Path Coefficients for Youth Rated Measures

\begin{tabular}{|c|c|c|c|c|c|c|}
\hline & $\begin{array}{c}\text { CBQ } \\
\text { Appraisal of } \\
\text { Parent and } \\
\text { RCMAS }\end{array}$ & $\begin{array}{c}\text { Parental } \\
\text { Acceptance } \\
\text { and } \\
\text { RCMAS }\end{array}$ & $\begin{array}{l}\text { Parental } \\
\text { Control and } \\
\text { RCMAS }\end{array}$ & $\begin{array}{l}\text { Positive } \\
\text { Friendships } \\
\text { and } \\
\text { RCMAS }\end{array}$ & $\begin{array}{l}\text { Negative } \\
\text { Friendship } \\
\mathrm{s} \text { and } \\
\text { RCMAS }\end{array}$ & $\begin{array}{l}\text { Social Skills } \\
\text { and RCMAS }\end{array}$ \\
\hline $\begin{array}{l}\text { Session } 4 \\
\text { (path a) }\end{array}$ & & -- & $0.18(0.18)$ & - & $0.15(0.36)$ & -- \\
\hline $\begin{array}{l}\text { Session } 6 \\
\text { (path b) }\end{array}$ & -- & -- & $0.72(0.74)$ & -- & -- & -- \\
\hline $\begin{array}{l}\text { Session } 8 \\
\text { (path c) }\end{array}$ & -- & $0.23(0.17)$ & -- & -- & -- & -- \\
\hline $\begin{array}{l}\text { Session } 10 \\
\text { (path d) }\end{array}$ & -- & -- & -- & -- & -- & -- \\
\hline $\begin{array}{l}\text { Session } 12 \\
\text { (path e) }\end{array}$ & -- & -- & -- & -- & -- & -- \\
\hline $\begin{array}{l}\text { Posttreatment } \\
\text { (path f) }\end{array}$ & $0.18(0.13)$ & -- & -- & $-.10(-0.20)$ & $0.13(0.27)$ & $-0.13(-0.25)$ \\
\hline
\end{tabular}


Table 5

Selected Contemporaneous Path Coefficients for Parent Rated Measures

\begin{tabular}{|c|c|c|c|c|c|c|}
\hline & $\begin{array}{c}\text { CBQ } \\
\text { Appraisal } \\
\text { of Parent } \\
\text { and } \\
\text { RCMAS }\end{array}$ & $\begin{array}{l}\text { Parental } \\
\text { Acceptanc } \\
\text { e and } \\
\text { RCMAS }\end{array}$ & $\begin{array}{l}\text { Parental } \\
\text { Control and } \\
\text { RCMAS }\end{array}$ & $\begin{array}{l}\text { Positive } \\
\text { Friendships } \\
\text { and } \\
\text { RCMAS }\end{array}$ & $\begin{array}{c}\text { Negative } \\
\text { Friendships } \\
\text { and RCMAS }\end{array}$ & $\begin{array}{l}\text { Social Skills } \\
\text { and RCMAS }\end{array}$ \\
\hline $\begin{array}{l}\text { Session } 4 \\
\text { (path a) }\end{array}$ & $0.32(0.20)$ & -- & -- & -- & -- & -- \\
\hline $\begin{array}{l}\text { Session } 6 \\
\text { (path b) }\end{array}$ & -- & $0.28(0.22)$ & -- & -- & $0.40(0.16)$ & -- \\
\hline $\begin{array}{l}\text { Session } 8 \\
\text { (path c) }\end{array}$ & $0.48(0.24)$ & -- & -- & -- & & -- \\
\hline $\begin{array}{l}\text { Session } 10 \\
\text { (path d) }\end{array}$ & -- & -- & -- & $0.17(0.16)$ & $0.38(0.17)$ & $0.16(0.21)$ \\
\hline $\begin{array}{l}\text { Session } 12 \\
\text { (path e) }\end{array}$ & -- & -- & $0.37(0.35)$ & -- & -- & -- \\
\hline $\begin{array}{l}\text { Posttreat- } \\
\text { ment } \\
\text { (path f) }\end{array}$ & $0.48(0.34)$ & -- & -- & -- & -- & $-0.09(-0.17)$ \\
\hline
\end{tabular}


Table 6

Selected Autoregressive Path Coefficients for Youth Rated Measures

\begin{tabular}{|c|c|c|c|c|c|c|c|}
\hline & $\begin{array}{c}\text { CBQ } \\
\text { Appraisal } \\
\text { of Parent }\end{array}$ & $\begin{array}{c}\text { CBQ } \\
\text { Appraisal } \\
\text { of Dyad } \\
\text { Conflict }\end{array}$ & $\begin{array}{c}\text { Parental } \\
\text { Acceptance }\end{array}$ & $\begin{array}{l}\text { Parental } \\
\text { Control }\end{array}$ & $\begin{array}{l}\text { Positive } \\
\text { Friendships }\end{array}$ & $\begin{array}{l}\text { Negative } \\
\text { Friendships }\end{array}$ & $\begin{array}{l}\text { Social } \\
\text { Skills }\end{array}$ \\
\hline $\begin{array}{l}\text { Session } 4 \text { and } 6 \\
\text { (path a) }\end{array}$ & $0.58(0.64)$ & $0.30(0.72)$ & $0.58(0.60)$ & $0.77(0.76)$ & $0.74(0.71)$ & $0.34(0.37)$ & $0.68(0.67)$ \\
\hline $\begin{array}{l}\text { Session } 6 \text { and } 8 \\
\text { (path b) }\end{array}$ & $0.67(0.69)$ & $0.42(0.48)$ & $0.71(0.66)$ & $0.85(0.81)$ & $0.63(0.59)$ & -- & $0.55(0.53)$ \\
\hline $\begin{array}{l}\text { Session } 8 \text { and } 10 \\
\text { (path c) }\end{array}$ & $0.64(0.57)$ & $0.55(0.65)$ & $0.50(0.58)$ & $0.57(0.61)$ & $0.20(0.23)$ & -- & -- \\
\hline $\begin{array}{l}\text { Session } 10 \text { and } 12 \\
\text { (path d) }\end{array}$ & $0.64(0.74)$ & -- & -- & $0.41(0.42)$ & $0.56(0.55)$ & $0.30(0.28)$ & $0.66(0.73)$ \\
\hline $\begin{array}{l}\text { Session } 12 \text { and } \\
\text { Posttreatment } \\
\text { (path e) }\end{array}$ & -- & -- & $4.60(0.77)$ & $2.60(0.67)$ & -- & -- & $2.42(0.28)$ \\
\hline
\end{tabular}

Note. Standardized coefficient shown in parentheses. RCMAS = Revised Children's Manifest Anxiety Scale (Reynolds \& Richmond, 1978); $\mathrm{CBQ}=$ Conflict Behavior Questionnaire (Prinz et al., 1979; youth version). ${ }^{*} p<.05 ; n s=$ nonsignificant. 
Table 7

Selected Autoregressive Path Coefficients for Parent Rated Measures

\begin{tabular}{|c|c|c|c|c|c|c|c|}
\hline & $\begin{array}{c}\text { CBQ } \\
\text { Appraisal } \\
\text { of Parent }\end{array}$ & $\begin{array}{l}\text { CBQ } \\
\text { Appraisal } \\
\text { of Dyad } \\
\text { Conflict }\end{array}$ & $\begin{array}{c}\text { Parental } \\
\text { Acceptance }\end{array}$ & $\begin{array}{l}\text { Parental } \\
\text { Control }\end{array}$ & $\begin{array}{c}\text { Positive } \\
\text { Friendships }\end{array}$ & $\begin{array}{l}\text { Negative } \\
\text { Friendships }\end{array}$ & Social Skills \\
\hline $\begin{array}{l}\text { Session } 4 \text { and } 6 \\
\text { (path a) }\end{array}$ & $0.42(0.68)$ & $0.42(0.51)$ & $0.67(0.58)$ & $0.74(0.75)$ & $0.53(0.49)$ & $0.49(.58)$ & $0.59(0.57)$ \\
\hline $\begin{array}{l}\text { Session } 6 \text { and } 8 \\
\text { (path b) }\end{array}$ & $0.51(0.50)$ & $0.46(0.39)$ & $0.31(0.38)$ & $0.81(0.80)$ & $0.55(0.54)$ & -- & -- \\
\hline $\begin{array}{l}\text { Session } 8 \text { and } 10 \\
\text { (path c) }\end{array}$ & $0.30(0.31)$ & -- & $0.39(0.38)$ & $0.38(0.42)$ & $0.45(.35)$ & $0.43(0.40)$ & $0.88(0.71)$ \\
\hline $\begin{array}{l}\text { Session } 10 \text { and } 12 \\
\text { (path d) }\end{array}$ & -- & -- & $0.46(0.51)$ & $0.40(0.39)$ & -- & $0.44(0.49)$ & -- \\
\hline $\begin{array}{l}\text { Session } 12 \text { and } \\
\text { Posttreatment } \\
\text { (path e) }\end{array}$ & $1.83(0.30)$ & $2.40(0.46)$ & $1.87(0.46)$ & -- & -- & -- & $1.66(0.21)$ \\
\hline
\end{tabular}

Note. Standardized coefficient shown in parentheses. RCMAS = Revised Children's Manifest Anxiety Scale (Reynolds \& Richmond, 1978); $\mathrm{CBQ}=$ Conflict Behavior Questionnaire (Prinz et al., 1979; youth version). $\mathrm{P}=$ Parent. ${ }^{*} p<.05 ; n s=$ nonsignificant. 
Table 8

Selected Lagged Path Coefficients for Youth Rated Measures

\begin{tabular}{|c|c|c|c|c|}
\hline Time Lag & $\begin{array}{c}\text { CBQ } \\
\text { Appraisal } \\
\text { of Dyad } \\
\text { Conflict } \\
\text { and } \\
\text { RCMAS }\end{array}$ & $\begin{array}{c}\text { Parental } \\
\text { Acceptance } \\
\text { and RCMAS }\end{array}$ & $\begin{array}{l}\text { Parental } \\
\text { Control } \\
\text { and } \\
\text { RCMAS }\end{array}$ & $\begin{array}{l}\text { Negative } \\
\text { Friendships } \\
\text { and } \\
\text { RCMAS }\end{array}$ \\
\hline $\begin{array}{l}\text { Session } 6 \text { to } 8 \\
\text { (path a ) }\end{array}$ & -- & -- & $0.22(0.23)$ & -- \\
\hline $\begin{array}{l}\text { Session } 6 \text { to } 10 \\
\text { (path b) }\end{array}$ & $0.97(0.25)$ & -- & -- & -- \\
\hline $\begin{array}{l}\text { Session } 6 \text { to } 12 \\
\text { (path c) }\end{array}$ & & -- & -- & $-0.10(-0.24)$ \\
\hline $\begin{array}{l}\text { Session } 8 \text { to } 10 \\
\text { (path d) }\end{array}$ & $-0.73(-0.15)$ & -- & -- & -- \\
\hline $\begin{array}{l}\text { Session } 6 \text { to } \\
\text { Posttreatment } \\
\text { (path e) }\end{array}$ & -- & $-1.78(-0.21)$ & -- & -- \\
\hline $\begin{array}{l}\text { Session } 8 \text { to } \\
\text { Posttreatment } \\
\text { (path } \mathrm{f} \text { ) }\end{array}$ & -- & -- & $2.13(0.44)$ & -- \\
\hline
\end{tabular}

Note. Standardized coefficient shown in parentheses. First variable named in the first row is the presumed causal influence, and second variable is the outcome. RCMAS = Revised Children's Manifest Anxiety Scale (Reynolds \& Richmond, 1978); CBQ = Conflict Behavior Questionnaire (Prinz et al., 1979; youth version). ${ }^{*} p<.05 ; n s=$ nonsignificant. 
Table 9

Selected Lagged Path Coefficients for Parent Rated Measures

\begin{tabular}{|c|c|c|c|c|c|c|c|}
\hline Time Lag & $\begin{array}{l}\text { CBQ Appraisal of } \\
\text { Parent and } \\
\text { RCMAS/P }\end{array}$ & $\begin{array}{c}\text { CBQ } \\
\text { Appraisal of } \\
\text { Dyad } \\
\text { Conflict and } \\
\text { RCMAS/P }\end{array}$ & $\begin{array}{c}\text { Parental } \\
\text { Acceptance and } \\
\text { RCMAS/P }\end{array}$ & $\begin{array}{c}\text { Parental } \\
\text { Control and } \\
\text { RCMAS/P }\end{array}$ & $\begin{array}{c}\text { Positive } \\
\text { Friendships and } \\
\text { RCMAS/P }\end{array}$ & $\begin{array}{c}\text { Negative } \\
\text { Friendships and } \\
\text { RCMAS/P }\end{array}$ & $\begin{array}{c}\text { Social Skills } \\
\text { and RCMAS/P }\end{array}$ \\
\hline $\begin{array}{l}\text { Sessions } 4 \text { to } 8 \\
\text { (path a) }\end{array}$ & -- & -- & & $0.27(0.27)$ & & -- & -- \\
\hline $\begin{array}{l}\text { Sessions } 4 \text { to } \\
10 \text { (path b) }\end{array}$ & -- & -- & $-0.43(-0.27)$ & & & -- & -- \\
\hline $\begin{array}{l}\text { Sessions } 4 \text { to } \\
12 \text { (path c) }\end{array}$ & $-0.68(-0.39)$ & -- & -- & -- & & -- & -- \\
\hline $\begin{array}{l}\text { Sessions } 4 \text { to } \\
\text { Posttreatment } \\
\text { (path d) }\end{array}$ & $2.84(0.34)$ & -- & -- & -- & & -- & -- \\
\hline $\begin{array}{l}\text { Sessions } 6 \text { to } 8 \\
\text { (path e) }\end{array}$ & -- & -- & -- & $-0.27(-0.27)$ & $0.21(0.16)$ & -- & \\
\hline $\begin{array}{l}\text { Session } 6 \text { to } \\
\text { posttreatment } \\
\text { (path } \mathrm{f} \text { ) }\end{array}$ & & $-4.11(-0.31)$ & & & & $-3.85(-0.28)$ & \\
\hline $\begin{array}{l}\text { Session } 8 \text { to } 10 \\
\text { (Path g) }\end{array}$ & -- & -- & -- & & & -- & $-0.25(-0.27)$ \\
\hline $\begin{array}{l}\text { Session } 8 \text { to } \\
\text { Posttreatment } \\
\text { (path h) }\end{array}$ & -- & -- & -- & $1.61(0.30)$ & & -- & -- \\
\hline Session 10 to & -- & $4.59(0.33)$ & -- & -- & & -- & -- \\
\hline
\end{tabular}


Posttreatment

(path i)

Session 12 to posttreatment (path j)

Note. Standardized coefficient shown in parentheses. First variable named in the first row is the presumed causal influence, and second variable is the outcome. RCMAS = Revised Children's Manifest Anxiety Scale (Reynolds \& Richmond, 1978); $\mathrm{CBQ}=$ Conflict Behavior Questionnaire (Prinz et al., 1979; youth version). $\mathrm{P}=$ Parent. ${ }^{*} p<.05 ; n s=$ nonsignificant. 
Figure 1. Conceptual Model

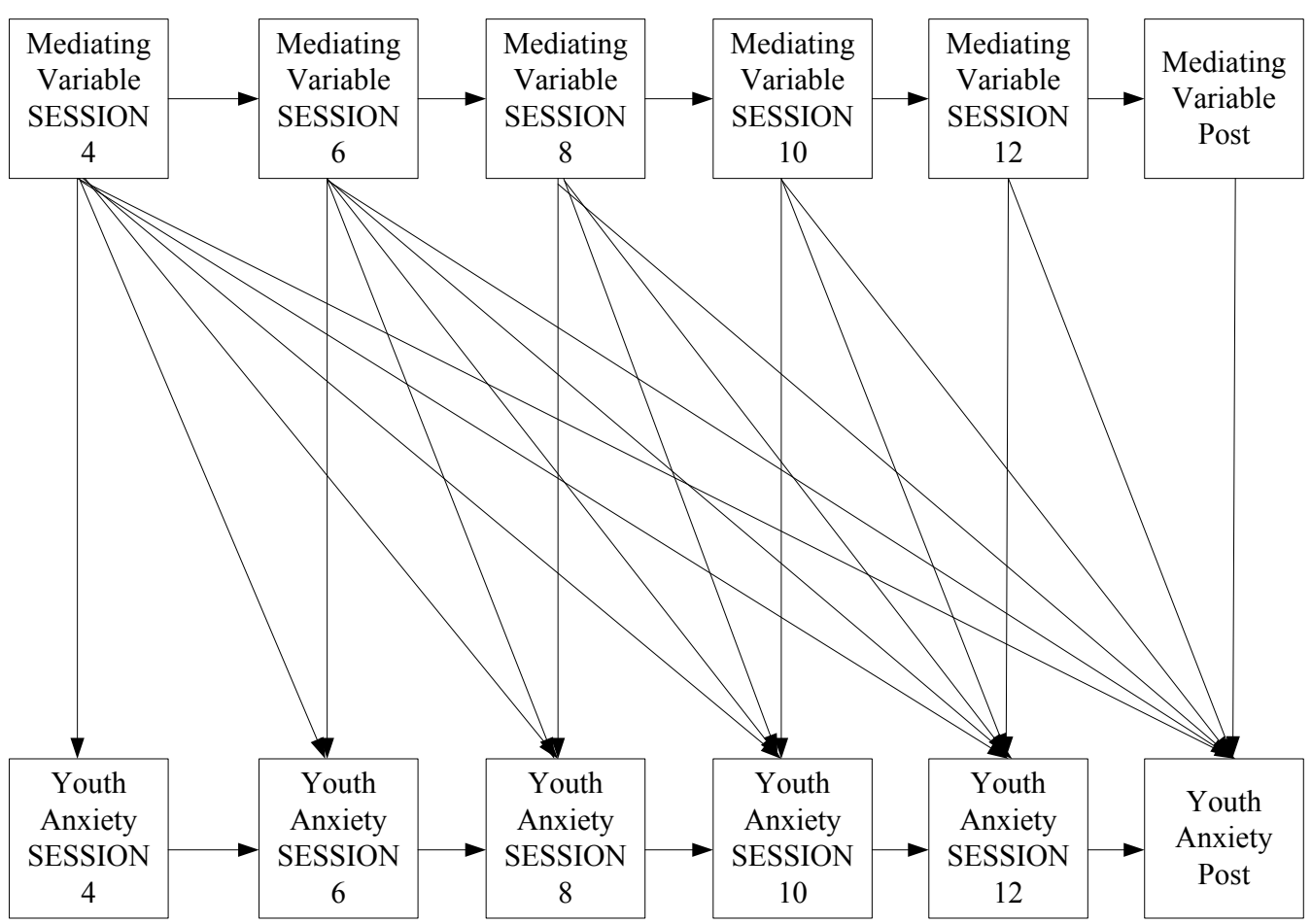

Mediating Variables, Parent and Child Reports:

CBQ 1-Appraisal of Mother

CBQ-Appraisal of Dyad

CRPBI/PRPBI- Acceptance,

CRPBI/PRPBI- Psychological Control

FQ-Positive Friendship Subscale

FQ-Negative Friendship Subscale

SSRS-Social Skills

POM= Primary Outcome Measure, Parent and Child Reports:

RCMAS =Youth Anxiety 


\section{References}

Achenbach, T. M. (1991). Manual for the Child Behavior Checklist and Revised Child Behavior Profile (Revised). Department of Psychiatry, University of Vermont, Burlington.

Achenbach, T. M. (1997). Manual for the Young Adult Self-Report and Young Adult Behavior Checklist. Burlington, VT: University of Vermont Department of Psychiatry.

Achenbach, T. M., \& Edelbrock, C. (1983). Manual for the Child Behavior Checklist and the Revised Child Behavior Profile. Burlington, VT: University of Vermont Department of Psychiatry.

Alfano, C. A., Pina, A. A., Villalta, I. K., Beidel, D. C., Ammerman, R. T, \& Crosby, L. E. (2009). Mediators and moderators of outcome in the behavioral treatment of childhood social phobia. Journal of the American Academy of Child and Adolescent Psychiatry, 48, 945-953.

Asher, S. R., \& Wheeler, V. A. (1985). Children's loneliness: A comparison of rejected and neglected peer status. Journal of Consulting and Clinical Psychology, 53, 500-505.

Baer, S. \& Garland, J. (2005). Pilot study of community-based cognitive behavioral group therapy for adolescents with social phobia. Journal of the American Academy of Child and Adolescent Psychiatry, 44, 258-264.

Baron, R. M., \& Kenny, D. A. (1986). The moderator-mediator variable distinction in social psychological research: Conceptual, strategic, and statistical considerations. Journal of Personality and Social Psychology, 51, 1173-1182.

Barrett, P. M. (1998). Evaluation of cognitive-behavioral group treatments for childhood anxiety disorders. Journal of Clinical Child Psychology, 27, 459-468.

Barrett, P. M., Dadds, M. R., \& Rapee, R. M. (1996). Family treatment of childhood anxiety: A controlled trial. Journal of Consulting and Clinical Psychology, 64, 333-342.

Barrett, P., Duffy, A., Dadds, M. \& Rapee, R. (2001). Cognitive-behavioral treatment of anxiety disorders in children: Long-term (6-year) follow-up. Journal of Consulting and Clinical Psychology, 69, 135-141.

Barmish, A. J. \& Kendall, P. C. (2005). Should parents be co-clients in cognitivebehavioral therapy for anxious youth. Journal of Clinical Child and Adolescent Psychology, 34, 569-581. 
Beesdo, K., Knappe, S., Pine, D. (2009). Anxiety and Anxiety disorders in children and adolescents: Developmental issues and implications for DSM-IV. Psychiatric Clinics of North America, 32(3), 483-524.

Beidel, D. C., Turner, S. M., \& Morris, T. L. (1999). Psychopathology of childhood social phobia. Journal of the American Academy of Child and Adolescent Psychiatry, 38, 643-650.

Beidel, D. C., Turner, S. M., \& Morris, T. L. (2000). Behavioral treatment of childhood social phobia. Journal of Consulting and Clinical Psychology, 68, 1072-1080.

Beidel, D. C., Turner, S. M., Sallee, F. R., Ammerman, R. T., Crosby, L. A., \& Pachak, S. (2007). SET-C versus fluoxetine in the treatment of childhood social phobia. Journal of the American Academy of Child and Adolescent Psychiatry, 46, 16221632.

Bernstein, G. A., \& Borchardt, C. M. (1991). Anxiety disorders of childhood and adolescence: A critical review. Journal of the American Academy of Child and Adolescent Psychiatry, 30, 519-532.

Bernstein, G. A., \& Garfinkel, B. D. (1986). School phobia: The overlap of affective and anxiety disorders. Journal of the American Academy of Child Psychiatry, 25, 235241 .

Bernstein, G. A., \& Garfinkel, B. D. (1988). Pedigrees, functioning, and psychopathology in families of school phobic children. American Journal of Psychiatry, 145, 7074.

Bierman, K., \& McCauley, E. (1987). Children's descriptions of their peer interactions: Useful information for clinical child assessment. Journal of Clinical Child Psychology, 16, 9-18.

Bird, H. R., Shaffer, D., Fisher, P., Gould, M. S. (1993). The Columbia Impairment Scale (CIS): Pilot findings on a measure of global impairment for children and adolescents. International Journal of Methods in Psychiatric Research, 3, 167176.

Birmaher, B., Khetarpal, S., Brent, D., Cully, M., Balach, L., Kaufman, J., et al. (1997). The Screen for Child Anxiety Related Emotional Disorders (SCARED): Scale construction and psychometric properties. Journal of the American Academy of Child and Adolescent Psychiatry, 36, 545-553.

Bodden, D. H. M., Bögels, S. M., Nauta, M. H., de Hann, E. Ringrose, J., Abbelboom, C., et al. (2008). Child versus family cognitive-behavioral therapy in clinically 
anxious youth: An efficacy and partial effectiveness study. Journal of the American Academy of Child and Adolescent Psychiatry, 47, 1384-1394.

Bögels, S. M., \& Siqueland, L. (2006). Family cognitive behavioral therapy for children and adolescents with clinical anxiety disorders. Journal of the American Academy of Child and Adolescent Psychiatry, 45, 134-141.

Chambless, D. L., \& Hollon, S. D. (1998). Defining empirically supported therapies. Journal of Consulting and Clinical Psychology, 66, 7-18.

Chansky, T. \& Kendall, P. (1997). Social expectancies and self-perceptions in anxietydisordered children. Journal of Anxiety Disorders, 11, 347-363.

Chorpita, B. F., \& Barlow, D. H. (1998). The development of anxiety: The role of control in the early environment. Psychological Bulletin, 124, 3-21.

Cliff, N., \& Earleywine, M. (1994). All predictors are "mediators" unless the other predictor is a "suppressor. " Unpublished manuscript.

Cobham, V. E., Dadds, M. R. \& Spence, S. H. (1998). The role of parental anxiety in the treatment of childhood anxiety. Journal of Consulting and Clinical Psychology, $66,893-905$.

Cole, D. A. \& Maxwell, S. E. (2003). Testing mediational effects with longitudinal data: Questions and tips in the use of structural equation modeling. Journal of Abnormal Psychology, 112, 558-577.

Costello, E. J., \& Angold, A. (1995). Developmental epidemiology. In D. Cicchetti \& D. Cohen (Eds.), Developmental psychopathology (Vol. 1, pp. 23-56). New York: Wiley.

Davis, M. D. (1985). The logic of causal order. In J. L. Sullivan and R. G. Niemi (Eds.), Sage university paper series on quantitative applications in the social sciences. Beverly Hills, CA: Sage Publications.

De Groot, J., Cobham, V., Leong, J., \& McDermott, B. (2007). Individual versus group family-focused cognitive-behavior therapy for childhood anxiety: Pilot randomized controlled trial. Australian and New Zealand Journal of Psychiatry, 41, 990-997.

Eddy, J. M. \& Chamberlain, P. (2000). Family management and deviant peer association as mediators of the impact of treatment condition on youth antisocial behavior. Journal of Consulting \& Clinical Psychology, 68, 857-863.

Endicott, J., Spitzer, R., Fleiss, J. \& Cohen, J. (1976). The global assessment scale. 
Archives of General Psychiatry, 33, 766-771.

Eysenck, S. B., \& Eysenck, H. J. (1968). The measurement of psychoticism: A study of factor stability and reliability. British Journal of Social and Clinical Psychology, 7, 286-294.

Flannery-Schroeder, E. C., \& Kendall, P. C. (2000). Group versus individual cognitive behavioral treatment for youth with anxiety disorders: A randomized clinical trial. Cognitive Therapy and Research, 24, 251-278.

Foa, E. B. \& Kozak, M. J. (1986). Emotional processing of fear: Exposure to corrective information. Psychological Bulletin, 99, 20-35.

Gallagher, H. M., Rabian, A. A. \& McCloskey, M. S. (2004). A brief group cognitivebehavioral intervention for social phobia in childhood. Journal of Anxiety Disorders, 18, 459-479.

Ginsburg, G. S., Silverman, W. K., \& Kurtines, W. M. (1996). Family involvement in treating children with phobic and anxiety disorders: A look ahead. Clinical Psychology Review.

Gollob, H. F. \& Reichardt, C. S. (1987). Taking account of time lags in causal models. Child Development, 58, 80-92.

Gollob, H. F., Reichardt, C. S., Collins, L. M. \& Horn, J. L. (1991). Interpreting and estimating indirect effects assuming time lags really matter. Journal of Consulting \& Clinical Psychology, 243-259.

Goodman, R. (1997). The Strengths and Difficulties Questionnaire: a research note. Journal of Child Psychology and Psychiatry, 38, 581-586.

Goodman, R.(1999). The extended version of the Strengths and Difficulties Questionnaire as a guide to child psychiatric caseness and consequent burden. Journal of Child Psychology and Psychiatry, 40, 791-799.

Gullone, E., King, N. J., \& Ollendick, T. H. (2001). Self-reported anxiety in children and adolescents: A three-year follow-up study. The Journal of Genetic Psychology, 162(1), 5-19.

Gresham, F. M., \& Elliott, S. N., (1990). Social Skills Rating System. American Guidance Service, Inc.: Circle Pines, MN.

Grusec, J. E., \& Davidov, M. (2007). Socialization in the family: The role of parents. In J. E. Grusec \& P. D. Hastings (Eds.), Handbook of socialization: Theory and research (pp. 284-308). New York: Guilford Press. 
Guerra, N. G. \& Slaby, R. G. (1990). Cognitive mediators of aggression in adolescent offenders: 2. Intervention. Developmental Psychology, 26, 269-277.

Hayes, A. M., Laurenceau, J.-P., Feldman, G., Strauss, J. L. \& Cardaciotto, L. (2007). Change is not always linear: The study of nonlinear and discontinuous patterns of change in psychotherapy. Clinical Psychology Review, 27, 715-723.

Hayward, C., Varardy, S., Albano, A. M., Thienemann, M., Henderson, L., \& Schatzberg, A. F. (2000). Cognitive-behavioral group therapy for social phobia in female adolescents: Results of a pilot study. Journal of the American Academy of Child and Adolescent Psychiatry, 39, 721-726.

Heimberg, R. G., Becker, R. E. (2002). Cognitive-behavioral group therapy for social phobia: Basic mechanisms and clinical strategies. Treatment manuals for practitioners. New York, NY, US: Guilford Press.

Hinshaw, S. P. (2007). Moderators and mediators of treatment outcome for youth with ADHD: Understanding for whom and how interventions work. Journal of Pediatric Psychology, 32, 664-675.

Huey, S. J., Henggeler, S. W., Brondino, M. J. \& Pickrel, S. G. (2000). Mechanisms of change in multisystemic therapy: Reducing delinquent behavior through therapist adherence and improved family and peer functioning. Journal of Consulting and Clinical Psychology, 68, 451-467.

Jaccard, J. \& Jacoby, J. (2009). Theory construction and model-building skills: A practical guide for social scientists. New York: Guilford Press.

Kazdin, A. E. (1994). Methodology, design, and evaluation in psychotherapy research. In A. E. Bergin \& S. L. Garfield (Eds.), Handbook of psychotherapy and behavior change (4th ed.) (pp. 19- 71). New York: Wiley.

Kazdin, A. E. (2007). Mediators and mechanisms of change in psychotherapy research. Annual Review of Clinical Psychology, 3, 1-27.

Kazdin, A. E. (2008). Evidence-based treatment and practice: New opportunities to bridge clinical research and practice, enhance the knowledge base, and improve patient care. American Psychologist, 63, 146-159.

Kazdin, A.E., Nock, M.K. (2003). Delineating mechanisms of change in child and adolescent therapy: Methodological issues and research recommendations, Journal of Child Psychology and Psychiatry 44, 1116-1129.

Kendall, P. C. (1984). Behavioral assessment and methodology. In G. T. Wilson, C. M. 
Franks, K. D. Braswell, \& P. C. Kendall (Eds.), Annual review of behavior therapy: Theory and practice (Vol. 9, pp. 39-94).New York: Guilford Press.

Kendall, P. C. (1994). Treating anxiety disorders in children: Results of a randomized clinical trial. Journal of Consulting and Clinical Psychology, 62, 200-210.

Kendall, P. C., Flannery-Schroeder, E., C., Panichelli-Mindel, S. M., Southam-Gerow, M., Henin, A., \& Warman, M. (1997). Therapy for youths with anxiety disorders: A second randomized clinical trial. Journal of Consulting and Clinical Psychology, 65, 366-380.

Kendall, P. C., \& Marrs-Garcia, A. (1999). Psychometric analyses of a therapy-sensitive measure: The Coping Questionnaire (CQ). Unpublished manuscript, Temple University.

Kendall, P. C., \& Treadwell, K. R. H. (2007). The role of self-statements as a mediator in treatment for youth with anxiety disorders. Journal of Consulting and Clinical Psychology, 75, 380-389.

Kingery, J. N., Erdley, C. A., Marshall, K. C., Whitaker, K. G., \& Reuter, Y. R., (2010). Peer experiences of anxious and socially withdrawn youth: An integrative review of the developmental and clinical literature. Clinical Child and Family Psychology Review, 13 (1), 91-128.

Kline, R. B. (2010). Principles and practices of structural equation modeling (3rd ed.). New York: Guilford Press.

Kolko, D. J., Brent, D. A., Baughter, M., Bridge, J., \& Birmaher, B. (2000). Cognitive and family therapies for adolescent depression: Treatment specificity, mediation, and moderation. Journal of Consulting and Clinical Psychology, 68, 603-614.

Kovacs, M. (1992). Children's Depression Inventory Manual. New York: Multi-Health Systems.

Kraemer, H. C., Wilson, T., Fairburn, C. G., \& Agras, S. (2002). Mediators and moderators of treatment effects in randomized clinical trials. Archives of General Psychiatry, 59, 877-883.

La Greca, A. M., Silverman, W. K. \& Lochman, J. E. (2009). Moving beyond efficacy and effectiveness in child and adolescent intervention research. Journal of Consulting and Clinical Psychology, 77, 3, 373-382.

La Greca, A. M. \& Stone, W. L. (1993). Social Anxiety Scale for Children - Revised: Factor structure and concurrent valididty. Journal of Clinical Child Psychology, $22,17-27$. 
Last, C. G., \& Strauss, C. C. (1990). School refusal in anxiety-disordered children and adolescents. Journal of the American Academy of Child \& Adolescent Psychiatry, 29, 31-35.

Last, C. G., Hansen, C. \& Franco, N. (1998). Cognitive-behavioral treatment of social phobia. Journal of the American Academy of Child \& Adolescent Psychiatry, 37, 404-411.

Last, C. G., Perrin, S., Hersen, M., \& Kazdin, A. E. (1996). A prospective study of childhood anxiety disorders. Journal of the American Academy of Child and Adolescent Psychiatry, 35, 1502-1510.

MacKinnon, D. P., Lockwood, C. M., Hoffman, J. M., West, S. G., \& Sheets, V. (2002). A comparison of methods to test mediation and other intervening variable effects. Psychological Methods, 7, 83-104.

Manassis, K. (1996), Keys to Parenting Your Anxious Child. New York: Barrons Educational Series.

Manassis, K., Mendlowitz, S. L., Scapillato, D., Avery, D., Fiksenbaum, L. \& Freire, M. (2002). Group and individual cognitive-behavioral therapy for childhood anxiety disorders: A randomized trial. Journal of the American Academy of Child and Adolescent Psychiatry, 41, 1423-1430.

Manassis, K., Avery, D., Butalia, S. \& Mendlowitz, S. (2004). Cognitive-behavioral therapy with childhood anxiety disorders: Functioning in adolescence. Depression and Anxiety, 19, 4, 209-216.

March, J. S., Parker, J., Sullivan, K., Stallings, P., \& Conners, K. (1997). The Multidimensional Anxiety Scale for Children (MASC): Factor structure, reliability and validity. Journal of the American Academy of Child and Adolescent Psychiatry, 36, 554-565.

Maxwell, S. E. \& Cole, D. A. (2007). Bias in cross-sectional analyses of longitudinal mediation. Psychological Methods, 12, 23-44 10.

Mauro, R. (1990). Understanding L. O. V. E. (Left out variables error): A method for estimating the effects of omitted variables. Psychological Bulletin, 108, 314-329.

Mendolowitz, S.L., Manassis, K., Bradley, S., Scapillato, D., Miezitis, S., Shaw, B.F. (1999). Cognitive-behavioral group treatments in childhood anxiety disorders: the role of parental involvement. Journal of the American Academy of Child and Adolescent Psychiatry, 38, 1223-1229. 
Muthén, L.K., \& Muthén, B.O. (2004). Mplus: The comprehensive modeling program for applied researchers. User’s guide (3rd ed.). Los Angeles: Muthén \& Muthén.

National Institutes of Health (1985). Global Improvement Scale. Psychopharmacological Bulletin, 21, 839-843.

Nishith, P., Resick, P. A. \& Griffin, M. G. (2002). Pattern of change in prolonged exposure and cognitive-processing therapy for female rape victims with posttraumatic stress disorder. Journal of Consulting \& Clinical Psychology, 70, 880886.

Parker, J. G., \& Asher, S. R. (1987). Peer relations and later personal adjustment: Are low-accepted children at risk? Psychological Bulletin, 102, 357-389.

Patterson, G. R. \& Forgatch, M. S. (1995). Predicting future clinical adjustment from treatment outcome andprocess variables. Psychological Assessment, 7, 275-285.

Pine, D. S., Cohen, P., Gurley, D., Brook, J., \& Ma, Y. (1998). The risk for earlyadulthood anxiety and depressive disorders in adolescents with anxiety and depressive disorders. Archives of General Psychiatry, 55, 56-64.

Prinz, R. J., Foster, S., Kent, R. N., \& O'Leary, K. D. (1979). Multivariate assessment of conflict in distressed and non-distressed mother-adolescent dyads. Journal of Applied Behavior Analysis, 12, 691-700.

Program for Prevention Research. (October 1992), Divorce Adjustment Project Documentation. Available from the Program for Prevention Research, Arizona State University, Tempe.

Rapee, R. M. (1997). Potential role in childrearing practices in the development of anxiety and depression. Clinical Psychology Review, 17, 47-67.

Rapee, R. M., Abbott, M. J., \& Lyneham, H. J. (2006). Bibliotherapy for children with anxiety disorders using written materials for parents: A randomized controlled trial. Journal of Consulting and Clinical Psychology, 74, 436-444.

Reynolds, C. R., \& Richmond, B. O. (1978). What I think and feel: A revised measure of children's manifest anxiety. Journal of Abnormal Child Psychology, 6, 271-280.

Ronan, K., Kendall, P. C. \& Rowe, M. (1994). Negative affectivity in children: Development and validation of a self-statement questionnaire. Cognitive Therapy \& Research, 18, 509-528.

Saavedra, L., Silverman, W. K., Morgan-Lopez, A. A., Kurtines, W. M. (2010). Cognitive behavioral treatment for childhood anxiety disorders: long-term effects 
on anxiety and secondary disorders in young adulthood. Journal of Child Psychology and Psychiatry 51(8). 924-934.

Schludermann, E., \& Schludermann, S. (1970). Replicability of factors in children's report of parent behavior (CRPBI). Journal of Psychology, 76, 239-249.

Schniering, C.A., \& Rapee, R.M. (2002). Development and validation of a measure of children's automatic thoughts: The Children's Automatic Thoughts Scale. Behaviour Research and Therapy: Behavioral Assessment Section, 40, 10911109.

Schwartz, R. M., \& Garamoni, G. L. (1986). A structural model of positive and negative states of mind: Asymmetry in the internal dialogue. In P. C. Kendall (Ed.), Advances in cognitive-behavioral research and therapy (Vol. 5, pp. 1-62). New York: Academic Press.

Shortt, A. L., Barrett, P. M. \& Fox, T. L. (2001). Evaluating the FRIENDS program: A cognitive-behavioral group treatment for anxious children and their parents. Journal of Clinical Child Psychology, 30, 525-535.

Silverman, W. K., \& Albano, A. M. (1996). Anxiety Disorders Interview Schedule for Children-IV (Child and Parent Versions). San Antonio, TX: Psychological Corporation.

Silverman, W. K., Cerny, J. A., \& Nelles, W. B. (1988). The familial influence in anxiety disorders: Studies on the offspring of patients with anxiety disorders. In B. B. Lahey \& A. E. Kazdin (Eds.), Advances in clinical child psychology, Vol.11 (pp. 223-248). New York: Plenum Press.

Silverman, W. K., Kurtines, W. M., Ginsburg, G. S., Weems, C. F., Rabian, B., \& Serafini, L. T. (1999a). Contingency management, self-control, and education support in the treatment of childhood phobic disorders: A randomized clinical trial. Journal of Consulting and Clinical Psychology, 67, 675-687.

Silverman, W. K., Kurtines, W. M., Ginsburg, G. S., Weems, C. F., Lumpkin, P. W., \& Hicks-Carmichael, D. (1999b). Treating anxiety disorders in children with group cognitive behavior therapy: A randomized clinical trial. Journal of Consulting and Clinical Psychology, 67, 995-1003.

Silverman, W. K., Kurtines, W. M., Ginsburg, G. S., Weems, C. F., Lumpkin, P. W., \& Hicks-Carmichael, D. (1999). Treating anxiety disorders in children with group cognitive behavior therapy: A randomized clinical trial. Journal of Consulting and Clinical Psychology, 67, 995-1003.

Silverman, W. K., Kurtines, W. M., Jaccard, J. \& Pina, A. (2009). Directionality of 
change in youth anxiety treatment involving parents: An initial examination. Journal of Consulting and Clinical Psychology.

Silverman, W. K., Pina, A. A., \& Viswesvaran, C. (2008). Evidence-based psychosocial treatments for phobic and anxiety disorders in children and adolescents. Journal of Clinical Child and Adolescent Psychology, 37, 105-130.

Simon, H. A. (1977). Models of discovery. Dordrecht, Holland: Reidel.

Siqueland, L., Kendall, P. C., \& Steinberg, L. (1996). Anxiety in children: Perceived family environments and observed family interactions. Journal of Clinical Child Psychology, 25, 225-237.

Spence, S. H. (1998). A measure of anxiety among anxious children. Behaviour Research and Therapy, 36, 545-566.

Spence, S. H., Donovan, C. \& Brechman-Toussaint, M. (1999). Social skills, social outcomes and cognitive features of childhood social phobia. Journal of Abnormal Psychology, 108, 211-221.

Spence, S. H., Donovan, C., \& Brechman-Toussaint, M. (2000). The treatment of childhood social phobia: the effectiveness of a social skills training-based, cognitive behavioural intervention, with and without parental involvement. Journal of Child Psychology and Psychiatry, 41, 713-726.

Spielberger, C.D. (1973). Manual for the State-Trait Anxiety Inventory for Children. Palo Alto, CA: Consulting Psychologists Press.

Spielberger, C. D., Gorsuch, R. L., \& Lushene, R. E. (1970) Manual for the State-Trait Anxiety Inventory (Self-Evaluation Questionnaire). Palo Alto, CA: Consulting Psychologists Press.

Strauss, C. C., Lahey, B.B., Frick, P., Frame, C. L., \& Hynd, G. (1988). Peer social status of children with anxiety disorders. Journal of Consulting and Clinical Psychology, 56, 137- 141.

Strauss, C. C., Lease, C. A., Kazdin, A. E., Dulcan, M. K., \& Last, C. G. (1989). Multimethod assessment of the social competence of children with anxiety disorders. Journal of Clinical Child Psychology, 18, 184-189.

Treadwell, K. R. H. \& Kendall, P. C. (1996). Self-talk in youth with anxiety disorders: States of mind, content specificity, and treatment outcome. Journal of Consulting and Clinical Psychology, 64, 941-950. 
Tang, T. Z. \& DeRubeis, R. J. (1999). Sudden gains and critical sessions in cognitivebehavioral therapy for depression. Journal of Consulting and Clinical Psychology, 67, 894-904.

Taylor, J.A. (1953). A personality scale of manifest anxiety. Journal of Abnormal Social Psychology, 48, 285-290.

Thienemann, M., Moore, P., \& Tompkins, K. (2006). A parent only group intervention for children with anxiety disorders: Pilot study. Journal of the American Academy of Child and Adolescent Psychiatry, 45, 37-46.

Treadwell, K. R. H. \& Kendall, P. C. (1997). Self-talk in youth with anxiety disorders: States of mind, content specificity, and treatment outcome. Journal of Consulting and Clinical Psychology, 64, 941-950.

Turner, S. M., Stanley, M. A., Beidel, B. C., \& Bond, L. (1989). The Social Phobia and Anxiety Inventory: Construct validity. Journal of Psychopathology and Behavioral Assessment, 11, 221-234.

Tzelgov, J., \& Henik, A. (1991). Suppression situations in psychological research: Definitions, implications, and applications. Psychological Bulletin, 109, 524-536.

Whaley, S.E., Pinto, A., \& Sigman, M. (1999). Characterizing interactions between anxious mothers and their children. Journal of Consulting and Clinical Psychology, 67, 826-836.

Weersing, V. R. \& Weisz, J. R. (2002). Mechanisms of action in youth psychotherapy. Journal of Child Psychology and Psychiatry, 43, 3-29.

Verduin, T. L. \& Kendall, P. S. (2008). Peer Perceptions and Liking of Children with Anxiety Disorders. J. Abn. Child Psychol, 36, 459-469.

Wittchen, H. U., Nelson, C. \& Lachner, G. (1998). Prevalence of mental disorders and psychosocial impairments in adolescents and young adults. Psychological Medicine, 28, 109-126.

Wood, J. J., Piacentini, J. C., Southam-Gerow, M., Chu, B.C., \& Sigman, M. (2006). Family cognitive behavioral therapy for child anxiety disorders. Journal of the American Academy of Child and Adolescent Psychiatry, 45, 314-321.

Wothke, W. (2000). Longitudinal and multi-group modeling with missing data. In T. D. Little, K. U. Schnabel, \& J. Baumert (Eds.) Modeling longitudinal and multiple group data: Practical issues, applied approaches and specific examples. Mahwah, NJ: Erlbaum. 
VITA

SANDRA WILLIAMS

EDUCATION

2005-present Florida International University, Miami, FL Doctoral Candidate in Developmental Psychology

Anticipate degree in 2010

1995-1996 Columbia University, New York, NY

M.A. in Developmental Psychology

1991-1995 Barry University, Miami, FL

B.S. in Psychology

\section{PUBLICATIONS}

Carter, R., Williams, S., \& Silverman, W.K. (2008). Cognitive and Emotional Facets of Test Anxiety in African American School Children. Cognition and Emotion.

Carter, R., Williams, S., Silverman, W.K., \& Jaccard, J. (in review). African American Elementary School Children's Performance on 'High Stakes' Achievement Tests: The Relative Effects of Test Anxiety and Anxiety Symptoms.

\section{CONFERENCE PRESENTATIONS}

Williams, S., Gray, C., \& Sagon, B. (2010). Heterogemeity in Ethno-Culturally Diverse Mothers At- Risk for Child Abuse. Paper presented at the APA annual convention, San Diego, California, August 2010

Williams, S., Motoca, L., Saintil, M., Carter, R., \& Silverman, W.K. (2008, November). Child anxiety sensitivity and its relation to perceived parenting behaviors. Poster presented at the annual Association for Behavioral and Cognitive Therapies conference, Orlando, FL.

Williams, S. (2008, February). Mother Daughter Communication and Its Influence on Risk Taking Behaviors Amongst Girls of Haitian Descent. Paper presented at the McKnight Doctoral Fellowship Program 2007 Mid-Year Research and Writing Meeting. 